\title{
INDEHISCENT regulates explosive seed dispersal
}

Anahit Galstyan ${ }^{1}$, Penny Sarchet ${ }^{2}$, Rafael Campos-Martin ${ }^{1,3}$, Milad Adibi ${ }^{1}$, Lachezar A.

Nikolov $^{1,4}$, Miguel Pérez Antón ${ }^{1}$, Léa Rambaud-Lavigne ${ }^{1}$, Xiangchao Gan ${ }^{1}$ and Angela

Hay $^{1 \dagger}$

${ }^{1}$ Max Planck Institute for Plant Breeding Research, Carl-von-Linné-Weg 10, 50829

Köln, Germany.

${ }^{2}$ Plant Sciences Dept, University of Oxford, South Parks Rd, Oxford OX1 3RB, UK.

${ }^{3}$ Institute of Medical Statistics and Computational Biology, Faculty of Medicine,

University of Cologne, Bachemer Str. 86, 50931 Cologne, Germany.

${ }^{4}$ Current address: Department of Cell and Developmental Biology, University of

California Los Angeles, 4018 TLSB Terasaki Life Sciences Building, 610 Charles E

Young Dr East, Los Angeles 90095-7239, USA.

${ }^{\dagger}$ Author for correspondence: e-mail address (hay@mpipz.mpg.de) phone: ++49 (221)

5062108, fax: ++49 (221) 5062674

Key words Cardamine hirsuta, Arabidopsis thaliana, fruit, explosive seed dispersal, INDEHISCENT, FRUITFULL 


\begin{abstract}
How traits evolve to produce novelty or stasis is an open question in biology. We investigate this question in Cardamine hirsuta, a relative of Arabidopsis thaliana that employs explosive fracture to disperse its seeds. This trait evolved through key morphomechanical innovations that distinguish the otherwise very similar, dehiscent fruit of these two species. Using CRISPR/Cas9, we show that dehiscence zone formation is absolutely required for explosive fracture in $C$. hirsuta, and is controlled by the bHLH transcription factor INDEHISCENT (IND). Using mutant screens, we identified the MADS-box transcription factor FRUITFULL (FUL) as a negative regulator of IND in $C$. hirsuta. Although FUL function is conserved in C. hirsuta, the consequences of IND misexpression differ in $f u l$ mutants of $C$. hirsuta versus $A$. thaliana. In ful mutants of both species, valve tissue is replaced by dehiscence zone tissue, which comprises two distinct cell types: lignified layer and separation layer cells. While A thaliana ful mutants develop stunted fruit with ectopic lignified layer cells, $C$. hirsuta ful mutants have elongated fruit with ectopic separation layer cells. We show that IND dose determines the proportion of these two cell types in ectopic dehiscence zones. We also show that the extent of ectopic lignification caused by IND mis-expression determines fruit length. Our findings indicate developmental system drift in the conserved gene network patterning dehiscent fruit in two related Brassicaceae species.
\end{abstract}




\section{Introduction}

Adaptations for dispersal are ubiquitous in nature. By moving individuals from one area to another, dispersal has important ecological and evolutionary consequences - including the ability to change or expand a species' range, which is especially relevant in today's context of climate change and landscape fragmentation (Kokko and Lopez-Sepulcre, 2006). Cardamine hirsuta uses an explosive mechanism to disperse its seeds in a wide radius around the parent plant (Hofhuis et al., 2016). While various flowering plants employ this strategy of explosive seed dispersal, it is restricted to Cardamine within the Brassicaceae family, and therefore absent in the model species Arabidopsis thaliana. We took advantage of this difference in seed dispersal strategy between two closely related species, to investigate the degree of conservation versus divergence in the gene regulatory networks that pattern explosive versus non-explosive fruit tissues.

In C. hirsuta, explosive fracture converts elastic potential energy in the fruit valves to kinetic coiling energy to eject the seeds (Hofhuis et al., 2016). The fracture runs along the seam that connects the coiling valve to the fruit. This connecting seam is called the dehiscence zone. The dehiscent fruit of both $C$. hirsuta and $A$. thaliana comprise two valves that are joined margin to margin along the replum and enclose the seeds. At maturity, the valves separate from the fruit along the dehiscence zone. In A. thaliana, this process occurs as the fruit dries, leaving the seeds exposed for subsequent dispersal by external agents (Dinneny and Yanofsky, 2005). So, the developmentally controlled process of dehiscence is temporally distinct from seed dispersal. In C. hirsuta, by contrast, dehiscence coincides with seed dispersal when the fruit explodes before drying. Therefore, the genes that pattern dehiscence zone formation are likely to influence explosive seed dispersal in C. hirsuta. 
The patterning mechanism that draws a line of cells with dehiscence zone fate along the valve margins, has been elucidated from genetic studies in A. thaliana (Dinneny and Yanofsky, 2005). The spatial precision of this patterning is controlled by a group of genes that promote dehiscence zone cell fate at the valve margins, and another group of genes that restrict this fate in surrounding tissues. Four genes encode transcription factors that promote dehiscence zone fate: the MADS-box proteins SHATTERPROOF 1 (SHP1) and SHP2, and the basic helix-loop-helix (bHLH) proteins INDEHISCENT (IND) and ALCATRAZ (ALC) (Liljegren et al., 2000; Liljegren et al., 2004; Rajani and Sundaresan, 2001). Expression of these four genes is mostly limited to the valve margins through repression by the MADS-box transcription factor FRUITFULL (FUL) in the valves and by the homeodomain transcription factor REPLUMLESS in the replum (Ferrandiz et al., 2000b; Liljegren et al., 2004; Roeder et al., 2003). This patterning mechanism ensures that three tissues differentiate post-fertilization in the fruit - valve, replum and dehiscence zone - with sharp borders between them.

Successful dehiscence depends on the differentiation of two specialized cell types in the dehiscence zone. A layer of lignified cells forms adjacent to the valve and a layer of non-lignified cells, capable of autolysis, forms adjacent to the replum (Spence et al., 1996). Lignified cell fate and complete dehiscence require the transcription factor NAC SECONDARY WALL THICKENING PROMOTING FACTOR 1 (Mitsuda and OhmeTakagi, 2008). While the non-lignified cells require the enzymatic activity of ARABIDOPSIS DEHISCENCE ZONE POLYGALACTURONASE 1 (ADPG1) and ADPG2 to degrade cell wall pectins, causing cells to separate and break (Ogawa et al., 
2009). In this way, the valve separates from the replum along a precise cell layer at the valve margin.

The key regulator of dehiscence zone cell fate in A. thaliana is IND (Liljegren et al., 2004). Loss of IND function causes loss of both the lignified layer and separation layer, while $A L C$ is required only for separation layer fate (Liljegren et al., 2004; Rajani and Sundaresan, 2001). The expression of both $I N D$ and $A L C$ is activated by SHP $1 / 2$ and these two target genes account for the majority of SHP1/2 function in valve margin development (Liljegren et al., 2000; Liljegren et al., 2004). However, each gene has distinct as well as overlapping functions, suggesting they form a nonlinear regulatory network (Liljegren et al., 2004). For example, IND forms heterodimers with the related bHLH proteins ALC and SPATULA (SPT), and ALC and SPT can also heterodimerise with each other and interact with DELLA repressor proteins (Arnaud et al., 2010; Gallego-Bartolome et al., 2010; Girin et al., 2011; Groszmann et al., 2011; Liljegren et al., 2004). The gibberellin (GA) biosynthesis gene GA3oxl and SPT are direct targets of IND (Arnaud et al., 2010; Girin et al., 2011). Therefore, local GA production in the valve margin leads to DELLA protein degradation and release of ALC, and likely SPT (Arnaud et al., 2010; Gallego-Bartolome et al., 2010). In this way, IND contributes to the activation of $A L C$ and SPT in the valve margin, where they regulate genes that cause cell separation along the dehiscence zone. An additional function of ALC and SPT is to feedback and repress IND gene expression (Lenser and Theissen, 2013). Although cellular resolution for these regulatory interactions is currently missing, this interplay between IND, DELLAs and ALC/SPT may provide a way to delimit the differentiation of separation and lignified layers in the dehiscence zone (Ballester and Ferrandiz, 2017). 
Transcriptional targets of IND also include the AGC3 kinase genes PINOID (PID) and WAG2 (Girin et al., 2011; Sorefan et al., 2009). Manipulating auxin levels in the IND expression domain - for example, increasing auxin synthesis by expressing the bacterial iaaM gene, or redistributing auxin by expressing $P I D$ or $W A G 2$ - results in indehiscent fruit (Sorefan et al., 2009; van Gelderen et al., 2016). PID and WAG2 regulate abundance of the PIN-FORMED 3 auxin efflux carrier at the plasma membrane, and, in this way, IND controls auxin distribution at the valve margin (Sorefan et al., 2009; van Gelderen et al., 2016). However, auxin responses are dynamic throughout valve margin development, with an initial maximum during dehiscence zone formation transitioning to a minimum during the differentiation of dehiscence zone cells (Li et al., 2019; Sorefan et al., 2009; van Gelderen et al., 2016). Therefore, it is still not clear exactly when and how IND regulates auxin to ensure successful dehiscence (Ballester and Ferrandiz, 2017).

IND appears to be a conserved regulator of fruit dehiscence within the Brassicaceae. IND is an atypical bHLH protein, found only in the Brassicaceae, and reverse genetics in Brassica rapa, Brassica oleracea, Capsella rubella and Lepidium campestre have shown that loss of IND function results in indehiscent fruit (Bailey et al., 2003; Dong et al., 2019; Girin et al., 2010; Heim et al., 2003; Kay et al., 2013; Lenser and Theissen, 2013; Toledo-Ortiz et al., 2003). IND expression in the valve margin of A. thaliana is governed by a 406-bp promoter sequence, and this conserved non-coding region has been identified in eight other Brassicaceae IND genes (Dong et al., 2019; Girin et al., 2010). In Capsella rubella, regulatory sequences outside of this region expand the domain of IND expression into the valves and partially contribute to the heart-shaped form of these fruit (Dong et al., 2019). Despite this derived expression domain, the function of FUL to repress 
IND expression is conserved in C. rubella (Dong et al., 2019). Given these examples, it is important to investigate the degree of conservation versus divergence in the gene regulatory networks that pattern diverse fruit within the Brassicaceae.

By taking a genetic approach in Cardamine hirsuta, we show that dehiscence zone formation is absolutely required for explosive fracture of the fruit. In this way, developmental regulators of dehiscence zone formation control explosive seed dispersal in C. hirsuta. We show that IND and FUL have conserved roles in patterning the dehiscent fruit of $C$. hirsuta. In $f u l$ mutants, dehiscence zones replace valves as a result of ectopic IND expression. However, this ectopic tissue comprises mostly separation layer cells in $C$. hirsuta ful, compared with lignified layer cells in A. thaliana ful. We show that IND dose determines the proportion of these two dehiscence zone cell types, suggesting that quantitative changes affecting $I N D$ expression in this conserved gene network may explain developmental system drift between two closely related species.

\section{Results}

\section{Dehiscence zone formation in C. hirsuta}

Dehiscence zones form in $C$. hirsuta fruit at the valve margins, adjacent to the replum, and comprise lignified and separation cell layers, similar to the non-explosive fruit of $A$. thaliana (Fig. 1A-D). Dehiscence zones form at the valve margins during early stages of fruit development (14-16, Fig. 1E-K) and differentiate lignified and separation layer cell types during later stages (17a-17b, Fig. L-O). A narrow band of cells at the valve margin begin to divide at stage 14 to produce a region of smaller cells at the valve margin (Fig. $1 \mathrm{~F}-\mathrm{K})$. The fruit surface starts to indent at this region of smaller cells between the replum 
and valve at stage 15 (Fig. 1G). Cell divisions are no longer observed after stage 16 (Fig. $1 \mathrm{~K}-\mathrm{O})$, suggesting that further growth of the dehiscence zone occurs via cell expansion.

To quantify cellular growth during dehiscence zone formation, we used live confocal imaging. We imaged epidermal cell outlines at four stages over seven days of fruit development and quantified cell area extension using MorphoGraphX in two replicate fruit series (Fig. 1P, Fig. S1) (Barbier de Reuille et al., 2015). We observed no cell division in these samples, indicating that fruit epidermal cells grew by expansion during this time. Growth was distributed across all three tissues of the fruit up until stage 17a, with maximal growth occurring between stages 16 and 17a (Fig. 1P). Cell area extension was higher in the longitudinal direction of the fruit in all tissues up to stage 17a (Fig. 1Q), resulting in elongation of the fruit to its maximal length. Growth ceased after stage $17 \mathrm{a}$ in all tissues except for the valve, which continued to grow in the transverse direction of the fruit (Fig. $1 P, Q)$, contributing to the expansion of fruit width. In summary, cells in the valve margin are significantly smaller than valve or replum cells (Fig. S2). They have a thin shape and grow predominantly in the longitudinal direction of the fruit, resulting in small, thin cells at the valve margin (Fig. 1Q, Fig. S2).

Cell differentiation of the dehiscence zone occurs during stage $17 \mathrm{ab}$ to form a lignified cell layer, adjacent to the valve, and a separation cell layer, adjacent to the replum (arrows, Fig. 1N). At this stage, lignification also occurs in endocarp $b$ cells in the valve and lignified cell types in the replum (Fig. 1N). The separation layer can be identified as a file of small cells flanked by lignified layer cells and larger replum cells (arrow, Fig. 1N). Cells along the separation layer physically detach from the lignified cell layer during stage 17b (dashed circle, Fig. 10). This complete maturation of the dehiscence zone coincides 
with when $C$. hirsuta valves acquire the capacity to explosively coil.

\section{Dehiscence zone is required for explosive pod shatter}

Given the spatial and temporal association between differentiation of the dehiscence zone and explosive fracture along this tissue, we tested whether dehiscence is required for explosive pod shatter. To generate $C$. hirsuta fruit that lack dehiscence zones, we performed CRISPR/Cas9 gene editing of C. hirsuta IND. We generated a C. hirsuta ind-1 allele with a single nucleotide insertion at position $361 \mathrm{bp}$ of the coding sequence (Fig. S3). This insertion introduces a frame shift at amino acid position 121 and a premature stop codon, producing a truncated protein of 182 amino acids with 62 amino acids of nonsense protein sequence at the C-terminus (Fig. S3). This truncated protein lacks the basic helixloop-helix domain that is critical for DNA binding and protein dimerization (CarreteroPaulet et al., 2010), suggesting that $C$. hirsuta ind-1 is a loss-of-function allele (Fig. S3). Plants homozygous for the recessive $C$. hirsuta ind-1 allele produced non-explosive, indehiscent fruit (Fig. 2A-B). These valves can coil when manually detached from the replum, but fail to eject the seeds (Fig. 2B). To demonstrate that loss of explosive seed dispersal in C. hirsuta ind-1 is caused by loss of IND function, we fully complemented the mutant phenotype with a $p C h I N D:: C h I N D: V E N U S$ transgene (Fig. 2I-K). Therefore, $C$. hirsuta IND is required for explosive pod shatter.

The indehiscent fruit of $C$. hirsuta ind -1 completely lack the narrow band of valve margin tissue, characterized in wild-type fruit by thin cells and no stomata (Fig. 2C, D, F, G). Using phloroglucinol to specifically stain lignin, we found no lignified cells at the valve margin of C. hirsuta ind-1 fruit (Fig. 2E, H). However, epidermal features and lignification patterns of valve and replum tissues appeared normal in mutant fruit (Fig. 2F-H). 
Therefore, IND functions as a master regulator of dehiscence zone formation in C. hirsuta as it does in A. thaliana.

To analyze the accumulation of $C$. hirsuta IND protein during fruit development, we imaged the $p C h I N D:: C h I N D:$ VENUS transgenic lines. A sharp boundary is established early in fruit development between IND expression in the valve margin and its absence from the rest of the valve (stage 12, Fig. 2J). This sharp boundary is maintained throughout subsequent stages of fruit development with strong expression of IND in the valve margins (stages 17a, Fig. 2K). In contrast to the valve, we observed IND expression extending from the valve margin part way into the replum (Fig. 2J-K). To map the DNA sequences required for tissue-specific expression of $C$. hirsuta IND, we generated transcriptional fusions using either $1885 \mathrm{bp}$ of non-transcribed promoter sequence ( $p C h I N D:: 3 x V E N U S$ ), which includes the conserved non-coding sequence that is sufficient for valve margin expression of A. thaliana IND (Girin et al., 2010) (Fig. S3), or an additional 84 bp of transcribed 5' UTR ( $p$ ChIND-UTR::3xVENUS) (Fig. 2L-M, Fig. S3). We found that valve marginspecific expression of $C$. hirsuta IND strictly requires the 84 bp 5'UTR (Fig. 2L), as the 1885 bp promoter fusion was expressed ubiquitously throughout the fruit (Fig. 2M). In summary, C. hirsuta IND accumulates in the valve margin prior to development of the dehiscence zone and is maintained throughout its differentiation.

$\underline{\text { Genetic screen for indehiscent mutants in C. hirsuta }}$

To identify additional regulators of dehiscence zone formation in C. hirsuta, we screened ethyl methanesulfonate-mutagenized plants for mutants with indehiscent fruit. We named an indehiscent mutant from this screen valveless because its fruit lacked valves (Fig. 3AB). Using map-based cloning, we identified a $\mathrm{C}$ to $\mathrm{T}$ nucleotide substitution in the $C$. 
hirsuta MADS-box gene FRUITFULL (FUL, gene identifier CARHR274590 (Gan et al., 2016)) that co-segregated with the valveless mutant phenotype (Fig. S4). This mutation introduces a premature stop codon that results in a truncated 143 amino acid protein that contains the MADS-box but not the K-box dimerization domain (Fig. S4). C. hirsuta FUL transcripts accumulate to their highest levels in the valves during fruit development and are reduced to $5 \%$ of wild-type levels in mutant fruit (Fig. 3D-E). In addition, silencing $C$. hirsuta FUL expression using VIGS, produced indehiscent fruit that lacked valve tissue and phenocopied the valveless mutant (Fig. S4). Moreover, the valveless mutant phenotype was fully complemented by introducing a $p C h F U L:$ ChFUL:GFP transgene (Fig. 3C). Taken together, these results show that valveless is a recessive, loss-of-function allele of C. hirsuta FUL, so we renamed the allele C. hirsuta ful-1.

The fruit of $C$. hirsuta ful-1 are comparable to wild type in length, but narrower in width (Fig. 3A-B). These mutant fruits lack valves, which are replaced by expanded regions of valve margin-like tissue (Fig. 3F-K). In wild-type fruit, the valve margin comprises thin cells with a smooth epidermal surface and no stomata (Fig. 3G). Valve cells have a striated epidermal surface, are wider than replum cells, and stomata are present in both valve and replum (Fig. 3F-G). Valve cells are absent from C. hirsuta ful-1 fruit, while replum and valve margin-like cells are present (Fig. 3I-J). The ectopic valve margin-like tissue in the mutant is thin and semi-transparent such that seeds are clearly visible through it (Fig. 3K). Replum size is also expanded in C. hirsuta ful-1 fruit, but despite this expansion in replum and valve margin tissues, the fruit remains narrow with very reduced locules in the absence of valves (Fig. 3L, N). As a consequence, the space available for seeds to develop is very constricted in $C$. hirsuta ful- 1 fruit, resulting in narrow, deformed 
seeds that are nonetheless fully viable (Fig. 3N, Fig. S5). We could not detect FUL transcripts in wild-type $C$. hirsuta seeds, and embryos developed normally in C. hirsuta ful-1 mutants up until maturity when space restrictions caused some embryos to bend abnormally (Figs. S4, S5). Therefore, the primary defect in C. hirsuta ful-1 fruit is a complete loss of valves and their replacement by valve margin-like tissue.

Comparison of wild-type valve with the valve margin-like tissue found in C. hirsuta ful-1 fruit, shows an absence of differentiated valve cell types in the mutant (Fig. 3M, O). Wild-type valves comprise the exocarp cell layer, approximately 7 mesocarp cell layers, a characteristic endocarp $b$ cell layer with asymmetric lignin deposition, and an endocarp $a$ cell layer adjacent to the seeds (Fig. 3M). In comparison, the ectopic valve margin that forms in place of valve in C. hirsuta ful-1, comprises 9-10 layers of small cells that resemble the replum-adjacent separation layer of the wild-type dehiscence zone (Fig. 3O). Additionally, cells with uniform lignification, similar to lignified cells of the wild-type dehiscence zone, are sometimes found in the ectopic valve margin (Fig. 5C). These differences in histology between $C$. hirsuta ful-1 and wild-type fruit are first observed at stage 12 and are clearly apparent by stage 14 when valve tissue starts to differentiate in wild type (Fig. S6). Taken together, our findings suggest that valve cell fate is not specified in C. hirsuta ful-1 and instead, this fruit tissue adopts dehiscence zone cell fates, mostly of the replum-adjacent separation layer.

\section{$\underline{\text { Homeotic conversion of valve to separation layer fate in } C \text {. hirsuta ful mutant }}$}

To investigate whether valve identity has switched to dehiscence zone identity in C. hirsuta ful-1, we examined the expression of valve margin identity genes in the mutant. pChIND::ChIND:VENUS accumulates in the valve margin but is strictly absent from outer 
layers of the valve in wild-type fruit (Fig. 4A, C, Fig. 2J-K). In C. hirsuta ful-1, pChIND::ChIND:VENUS accumulates throughout the ectopic valve margin (Fig. 4B, D), indicating a homeotic switch in cell fate from valve to valve margin. We used a pAtIND::AtIND:GUS reporter to show that ectopic IND expression is already obvious by stage 12 in C. hirsuta ful-1 (Fig. S6), which coincides with the first differences in histology between C. hirsuta ful-1 mutant and wild-type fruit (Fig. S6).

A second bHLH protein that acts in the valve margin in A. thaliana is ALC (Rajani and Sundaresan, 2001). We observed strong expression of $p C h A L C: \because C h A L C: V E N U S$ in the valve margin of wild-type $C$. hirsuta fruit and throughout the ectopic valve margin in C. hirsuta ful-1 (Fig. 4E-F). In wild-type fruit, we observed a sharp boundary between expression of $C$. hirsuta ALC in the valve margin and its absence from the replum, with expression extending from the valve margin part way into the valve (Fig. 4E). We also observed non-specific expression of $p C h A L C:: C h A L C: V E N U S$ in stomata throughout the fruit (Fig. 4E). A third gene that confers valve margin identity in A. thaliana is the MADSbox gene SHP2 (Liljegren et al., 2000). We found expression of $p C h S H P 2:: G U S$ in the valve margin of wild-type fruit and throughout the ectopic valve margin in C. hirsuta ful1 (Fig. S6). Therefore, our results using three different marker genes confirm that valve cell fate is replaced by dehiscence zone fate in C. hirsuta ful-1 fruit.

The dehiscence zone is comprised of two cell types: lignified and separation layer cells (Fig. 1). We hypothesized that the small, non-lignified cells found in the expanded dehiscence zones in C. hirsuta ful-1 are separation layer cells (Fig. 3O). To test this, we used the Sytox Blue dead cell stain to identify separation layer cells, which are dead at maturity, in wild-type and C. hirsuta ful-1 fruit. Under UV excitation, we observed bright 
speckles of Sytox Blue fluorescence in the separation layer of the wild-type dehiscence zone and throughout the expanded dehiscence zones in C. hirsuta ful-1 (Fig. 4I-J). We also observed lignin autofluorescence in the lignified layer of the wild-type dehiscence zone in both the absence and presence of stain, but not in the expanded dehiscence zones of $C$. hirsuta ful-1 (Fig. 4G-I). Therefore, the dehiscence zones that replace valve tissue in $C$. hirsuta ful-1 comprise mostly separation layer rather than lignified layer cells.

To further characterize separation layer identity in $C$. hirsuta fruit, we generated transcriptional profiles of stage $17 \mathrm{ab}$ wild type, ind -1 , and $f u l-1$ fruit. Seeds were dissected out of the fruit and not included. To identify valve margin genes that are likely to be associated with the separation layer, we combined differential expression and cluster analysis (Fig. 4K). Given that the ectopic valve margin tissue in C. hirsuta ful-1 has separation layer identity, we predicted that genes downregulated in ind-1, but upregulated in ful-1 may be associated with the separation layer. We selected cluster 2 from eight clusters identified in the data, because it showed this predicted pattern of gene expression (Fig. 4K, Fig. S7, Table S3). By comparing cluster 2 with 558 genes that are differentially expressed between wild type and ind-1 (Table S4), we identified 97 shared genes (Fig. 4K, Table S5, Fig. S7). We used gene ontology (GO) analysis to determine that the most significantly enriched process in this gene set is transcriptional regulation (3 GO terms including GO:0006355, p-value 5.43E-04; Table S6). These GO terms include the related bHLH transcription factor genes IND, SPT, HECATE2 and HEC3 (Table S6). Cell wall organization is another process enriched in this gene set (GO:0071555, p-value 0.092), and includes the polygalacturonase gene $A D G P 1$ that is required to degrade pectins and allow cell separation along the dehiscence zone (Ogawa et al., 2009). Therefore, the separation 
layer transcriptome of stage $17 \mathrm{ab}$ C. hirsuta fruit is enriched for transcription factors and cell wall modifying enzymes.

We followed a similar approach to characterize valve tissue identity. By clustering genes that are similarly expressed between $C$. hirsuta wild type and ind-1, but downregulated in ful-1, we aimed to enrich for genes associated with the absence of valve, rather than the presence of ectopic valve margin in C. hirsuta ful-1. We selected cluster 3 because it showed this predicted pattern of gene expression (Fig. 4K, Fig. S7, Table S3). By comparing cluster 3 with 3505 genes that are differentially expressed between wild type and ful-1 (Table S7), we identified 1367 genes in common (Fig. 4K, Table S8, Fig. S7). $F U L$ is one of the most significantly differentially expressed genes in this cluster, and contributes, together with other transcription factor and receptor kinase genes, to the enriched GO term cell differentiation (GO:0030154, p-value 0.011, Table S9). The most significantly enriched processes in cluster 3 are associated with the cell wall (GO:0071555, p-value 9.13E-13), secondary cell wall (GO:0009834, p-value 3.56E-12), lignin biosynthesis (GO:0009809, p-value 1.1E-9), and cuticle development (GO:0042335, pvalue 2.79E-4), suggesting that major cell wall remodelling occurs during the differentiation of valve-specific cell types (Table S9). Photosynthesis is another process enriched in this gene set (GO:0015979, p-value 1.95E-5), suggesting a high contribution of the valve to the photosynthetic activity found in fruit pods (Brazel and O'Maoileidigh, 2019). Therefore, the valve transcriptome of stage $17 \mathrm{ab} C$. hirsuta fruit reflects the differentiation and function of valve-specific cell types.

\section{Conservation of FUL function between $A$. thaliana and C. hirsuta}

In both $C$. hirsuta and $A$. thaliana, FUL functions in the fruit to specify valve identity by 
repressing valve margin identity genes such as IND (Fig. 4A-D) (Ferrandiz et al., 2000b; Liljegren et al., 2004). Yet FUL loss of function has different consequences for final fruit morphology in the two species (Fig. 5A). The strong ful-1 allele in A. thaliana has severely stunted fruit valves with twisted repla (Gu et al., 1998), which differs dramatically from the straight, elongated fruit of $C$. hirsuta ful-1 (Fig. 5A, Fig. S8). An allelic series in $A$. thaliana shows that ful phenotypes differ according to allelic severity in the extent to which the valves are replaced by dehiscence zone identity (Ferrandiz et al., 2000a). This suggests that the complete homeotic conversion of valve to dehiscence zone identity in the elongated fruit of C. hirsuta ful-1 is likely to represent a strong, rather than weak, ful phenotype.

An important difference between the ectopic dehiscence zone that forms in $A$. thaliana versus $C$. hirsuta ful- 1 mutants is the cell type identity. The majority of this ectopic tissue has separation layer cell identity with some lignified cells in C. hirsuta ful-1, while in A. thaliana ful-1, this tissue has mostly lignified layer cell identity with some nonlignified, separation layer cells (Fig. 5B-C, Fig. S8). This suggests that although both species produce wild-type dehiscence zones with lignified and separation layers (Fig. 1), the ectopic dehiscence zone formed in the absence of FUL, is shifted towards separation layer identity in C. hirsuta and lignified layer identity in A. thaliana. To investigate whether this reflects a degree of divergence in $F U L$ function between species, we complemented ful-1 mutants from $C$. hirsuta and A. thaliana with the FUL genomic locus from both $C$. hirsuta and $A$. thaliana. We found that a $p C h F U L:: g C h F U L: V e n u s$ transgene, containing $6800 \mathrm{bp}$ of upstream promoter sequence, complemented fruit length and dehiscence in $C$. hirsuta ful-1 (Figs. 3C, 5D). We observed similar complementation of C. hirsuta ful-1 with a pAtFUL::gAtFUL:Venus transgene containing 1893 bp of upstream promoter sequence 
(Fig. 5D). By generating chimeric constructs between the FUL promoter and gene sequences of each species, we showed that fruit of $C$. hirsuta ful-1 were fully complemented by a $p C h F U L:: g A t F U L:$ Venus transgene (Fig. 5D). Therefore, C. hirsuta and $A$. thaliana FUL genes are both sufficient to complement $C$. hirsuta ful-1. These experiments also demonstrated that the FUL promoter sequence caused a small but consistent difference in fruit length between A. thaliana ful-1 complementation lines (Fig. S9). The 6800 bp promoter sequence of $C$. hirsuta FUL restored A. thaliana ful-1 fruit length closer to wild type than the 1893 bp promoter sequence of $A$. thaliana FUL (Fig. S9), suggesting that the shorter promoter sequence is insufficient for full complementation. We found that the complementing FUL-Venus fusion proteins expressed strongly in the valves of $C$. hirsuta fruit (Fig. 5E-G). The 6800 bp promoter sequence of $C$. hirsuta FUL directed valve-specific expression of both $C$. hirsuta and A. thaliana FUL, in addition to non-specific expression in stomata (Fig. 5E-F). In comparison, expression driven by the shorter $A$. thaliana FUL promoter was not valve-specific, but extended through the valve margin and replum (Fig. 5G), suggesting that this 1893 bp promoter sequence is insufficient to drive correct expression. Overall, these results indicate a high degree of conservation in FUL function between $C$. hirsuta and A. thaliana.

\section{C. hirsuta IND is sufficient for separation and lignified layer cell types}

To investigate whether the ectopic expression of IND in C. hirsuta ful-1 is responsible for the ectopic dehiscence zones that replace valves in this mutant, we generated ful-1; ind-1 double mutants in $C$. hirsuta. Double mutant fruit resembled ind-1 single mutants; valvelike tissue with epidermal stomata, expanded cells and vascular bundles, replaced the ectopic dehiscence zones found in C. hirsuta ful-1 (Fig. 6A-H, L-M, O). Therefore, ectopic 
IND expression is responsible for the ectopic dehiscence zones, which have mostly separation layer cell fate, in C. hirsuta ful-1.

To investigate whether $C$. hirsuta IND is sufficient to specify the lignified layer cell type of dehiscence zones, we expressed $C$. hirsuta IND broadly in wild-type plants using the CaMV $35 S$ promoter. These $p 35 S::$ ChIND fruit look like C. hirsuta ful-1 fruit with non-explosive valves that resemble dehiscence zone tissue (Fig. 6I). But unlike C. hirsuta ful-1, the valves of $p 35 S:: C h I N D$ fruit are ectopically lignified, indicating that $C$. hirsuta $I N D$ is sufficient to specify the lignified layer cell type of dehiscence zones (Fig. 6L-N). The lignified valves of $p 35 S:: C h I N D$ fruit retain epidermal features of valve tissue, such as stomata (Fig. 6K). These fruits also form valve margins that lack stomata and comprise smooth, elongated, cells (Fig. 6K). The presence of non-lignified, separation layer cells at the valve margin may explain why $p 35 S:: C h I N D$ fruit are not indehiscent like $C$. hirsuta ful- 1 but form a functional dehiscence zone between the replum and the lignified valves (Fig. 6J, N). Fruit length is significantly reduced in $p 35 S:: C h I N D$ and is associated with ectopic lignification of the valve (Fig. 6N, P). This result lends support to the idea that the lignified layer cells that form in the ectopic dehiscence zones of $A$. thaliana ful- 1 fruit contribute to their severe reduction in fruit length (Fig. 5A-B, Fig. S8, Fig. S9) (Liljegren et al., 2004). However, C. hirsuta ful-1 fruit also show a slight but significant reduction in length compared to wild type, which is not restored in C. hirsuta ful-1; ind-1 double mutants (Fig. 6P). This difference in fruit length is not associated with significant differences in seed number between genotypes (Fig. S9), suggesting that it is not caused by differential seed set (Cox and Swain, 2006; Ripoll et al., 2019). Therefore, FUL may have a small but significant effect on fruit growth in $C$. hirsuta that is independent of IND, 
similar to A. thaliana (Ripoll et al., 2015).

To further investigate the link between ectopic IND gene expression and fruit length, we induced $I N D$, driven by its own promoter, in a ful-1; ind-1 background in $C$. hirsuta. Given that A. thaliana IND fully complements the C. hirsuta ind-1 mutant (Fig. S10), we took advantage of a dexamethasone-inducible construct of $A$. thaliana IND (pAtIND:GR-pOp6:AtIND (Li et al., 2018)). Using increasing concentrations of dexamethasone to induce IND expression, we found a corresponding decrease in fruit length (Fig. 6Q). This quantitative relationship between IND expression and fruit length was associated with the formation of small valve margin cells in place of the larger valvelike cells observed in mock-treated fruit (Fig. S10). Moreover, the ectopic valve margin tissue in the shortest fruit, caused by high levels of IND expression, contained a greater proportion of lignified cells (Fig. S10). This indicates that different levels of ectopic IND expression are associated with different dehiscence zone cell fates. For example, we found in $C$. hirsuta that high levels of ectopic IND expression $(35 S:: C h I N D)$ causes mostly lignified layer cell fate, while much lower levels of ectopic IND (C. hirsuta ful-1) causes mostly separation layer cell fate, and intermediate levels of ectopic IND (dexamethasonetreated C. hirsuta ful-1; ind-1; pAtIND:GR-pOp6:AtIND) causes a mixture of both cell fates (Fig. 6, Fig. S10). These findings suggest that levels of IND activity may contribute to the specification of valve margin cells as having lignified or separation layer fates.

\section{Discussion}

We showed that dehiscence zone formation is regulated by the bHLH protein IND in $C$. hirsuta, and is necessary for explosive fracture of the fruit. Without dehiscence zones, the 
fruit of C. hirsuta ind mutants are non-explosive. However, these mutant fruit valves coil when manually separated from the replum, indicating that they generate tension. Therefore, formation of a dehiscence zone along the valve margin is required to weaken the attachment between valve and replum in order to release this tension by valve coiling. Thus, by patterning dehiscence zone cell fate, IND regulates explosive seed dispersal in C. hirsuta. Explosive seed dispersal is a key trait that distinguishes C. hirsuta from its close relative $A$. thaliana. Through a forward genetics screen for indehiscent mutants in $C$. hirsuta, we recovered FUL as a negative regulator of genes that promote dehiscence zone fate at the valve margins, including $I N D, A L C$ and $S H P 2$. Therefore, the gene regulatory networks that pattern explosive versus non-explosive fruit tissues are conserved between C. hirsuta and A. thaliana, but we also identified divergence. Loss of $F U L$ function results in cell fate transformations from valve to dehiscence zone in each species, but this fate is predominantly that of lignified layer cells in A. thaliana, and separation layer cells in $C$. hirsuta. This difference has profound consequences for ful fruit morphology between species, resulting in severely stunted fruit with twisted repla in A. thaliana (Gu et al., 1998), versus straight, elongated fruit in $C$. hirsuta. We show a quantitative relationship between ectopic IND expression and fruit length in C. hirsuta that correlates with the extent of ectopic lignification. Thus, the transformation to small, dehiscence zone cells with lignified layer fate impedes fruit expansion in both species (Liljegren et al., 2004). In this way, ful mutant fruit look very different between $C$. hirsuta and $A$. thaliana due to differences in the regulation of IND activity that are revealed in the absence of repression by FUL.

Overall conservation of the fruit patterning network between $C$. hirsuta and $A$. thaliana allows both species to produce equivalent patterning outputs despite divergence 
over evolutionary time - a concept called developmental system drift (Homann et al., 2009; True and Haag, 2001; Wotton et al., 2015). In order for system drift to occur, there must be different network genotypes that produce the same patterning outcome. For example, the repression of IND by FUL is conserved in A. thaliana, C. hirsuta and Capsella rubella, and is necessary for patterning the dehiscence zone in all three species (Dong et al., 2019; Liljegren et al., 2004). But FUL-independent regulation of IND may diverge more readily between species. For example, cis-regulatory changes in Capsella rubella IND cause its expression domain to expand into the fruit valves, where it activates the auxin biosynthesis genes TAA1 and YUCCA9 to influence fruit shape (Dong et al., 2019). A SUMO protease, HEARTBREAK, also participates in this process and stabilises Capsella rubella IND protein levels via de-SUMOylation (Dong et al., 2020). Therefore, both the levels and domain of IND expression can be regulated independently of FUL and diverge between species. In this study, we showed that manipulating IND expression levels shifts the balance of dehiscence zone cell fates. By quantitatively increasing the ectopic expression of IND in C. hirsuta fruit, we re-created the differences observed between elongated fruit lacking ectopic lignin, that are typical of $C$. hirsuta ful, and stunted fruit with ectopic lignin, which typify $A$. thaliana ful. This suggests that system drift between $C$. hirsuta and $A$. thaliana may have produced different network genotypes that quantitatively affect IND gene expression.

A key output of the fruit patterning network is to produce sharp borders between tissues. In $A$. thaliana fruit, IND expression reflects these sharp tissue boundaries, being restricted to the valve margin and excluded from both valve and replum (Li et al., 2018; Liljegren et al., 2004). However, in $C$. hirsuta fruit, the valve margin expression of $C$. 
hirsuta IND and ALC only produced a sharp boundary on one side of the valve margin. Specifically, C. hirsuta IND expression is excluded from the valve, but extends into the replum, while ALC expression is excluded from the replum, but extends into the valve (Fig. 4A, C, E). Therefore, the sharp borders of the dehiscence zone in C. hirsuta fruit are not precisely reflected by the expression domains of either IND or ALC alone. Full complementation of $C$. hirsuta ind -1 by the more restricted valve margin expression of $A$. thaliana IND (Fig. S10), suggests that this is the functional domain of IND expression in C. hirsuta fruit. However, these expression differences could also reflect how the same patterning output is produced in different ways in $C$. hirsuta vs $A$. thaliana fruit. For example, the combination of both IND and ALC may be required to define a sharp border on both sides of the dehiscence zone in C. hirsuta.

We gained new insights into the transcriptomes of separation layer and valve tissues of the fruit by leveraging both ind and ful mutants in C. hirsuta. The separation layer transcriptome was characterized by transcription factors and cell wall enzymes, including genes with known functions in this cell type such as IND, SPT and ADPG1 (Girin et al., 2011; Liljegren et al., 2004; Ogawa et al., 2009). Other genes in the enriched cell wall term GO:0071555, such as the xyloglucan endotransglucosylase/hydrolases $X T H 3$ and $X T H 28$ (Table S6), could be investigated for possible functions in the separation layer or as markers for this cell type in C. hirsuta fruit. Similarly, transcripts such as FUL that were enriched in the valve, reflected the differentiation and function of valve-specific cell types. Future studies could investigate genes in the enriched lignin biosynthesis term GO:0009809, such as LACCASE4, 11 and 17 (Table S9), as possible markers for the asymmetrically lignified endocarp $b$ cell type in $C$. hirsuta fruit valves. Approximately 
$10 \%$ of the top 50 differentially expressed genes in each cluster lacked an annotation or a clear ortholog in A. thaliana (Tables S5, S8), which may indicate a role for C. hirsutaspecific genes in fruit valve and separation layer development. Identifying new genes that act in the explosive fruit of $C$. hirsuta, and how these genes act in relation to IND and $F U L$, will further our understanding of how the balance of conservation versus divergence in fruit gene regulatory networks produced different seed dispersal strategies during evolution.

\section{Materials and Methods}

Plant material and growth conditions. C. hirsuta reference Oxford (Ox) accession, herbarium specimen voucher Hay 1 (OXF) (Hay and Tsiantis, 2006), and A. thaliana Landsberg erecta accession were used throughout unless indicated. Gene identifiers in the C. hirsuta genome assembly (Gan et al., 2016): FUL, CARHR274590; IND, CARHR248170; $\quad A L C, \quad$ CARHR280540; CLATHRIN/AP2M, CARHR174880; PHYTOENE DESATURASE, CARHR220290. A. thaliana ful-1 mutant (Gu et al., 1998) was obtained from the Arabidopsis Biological Resource Center, accession number CS3759. All plants were grown in long day conditions in the greenhouse: $16 \mathrm{~h}$ at $22^{\circ} \mathrm{C}: 8$ h at $20^{\circ} \mathrm{C}$, light: dark.

\section{EMS mutagenesis, mutant screening, genetic mapping and gene identification. $C$.}

hirsuta seeds were washed in $0.1 \%$ Triton ${ }^{\circledR}$ X-100, treated with either $0.18 \%(15 \mathrm{mM})$ or $0.36 \%$ (30 mM) ethyl methane sulphonate (EMS) in water for 10 hours, repeatedly washed with water, and pipetted onto soil as previously described (Hofhuis et al., 2016). Seed was collected from all fertile M1s, giving 895 M2 lines, of which 32145 M2 seeds were planted 
and screened for indehiscence. To map the indehiscent ful-1 mutation, homozygous mutants were crossed to the Wa accession and F1 plants were selfed to generate $743 \mathrm{~F} 2$ plants. DNA was extracted from 148 ful-1 mutants in this F2 and the mutant locus was mapped to a $11.7 \mathrm{cM}$ interval flanked by PCR markers m229 and m306 at the bottom of chromosome 8 . Further mapping delimited a $2.7 \mathrm{cM}$ interval flanked by PCR markers fd04 and m690, which corresponded to a region of chromosome 5 in A. thaliana that contained 33 annotated genes (TAIR10), including FUL, AT5G60910. Sanger sequencing identified a $\mathrm{C}$ to $\mathrm{T}$ single nucleotide change at position 429 of the full length FUL CDS in C. hirsuta ful-1, predicted to convert a Gln residue to a stop codon and produce a truncated 143 amino acid protein. A CAPS marker was designed to distinguish this SNP from the wild type Ox and Wa sequence and was shown to co-segregate with the ful-1 phenotype in $C$. hirsuta.

CRISPR-Cas9 mutagenesis. SgRNA-IND (5'-AAGCGACGATCCTCAGACGGTGG3'), located upstream of the HEC domain in C. hirsuta IND, was subcloned into pYB196 (Hyun et al., 2015) to generate a pU6:sgRNA-ChIND/pICU2:Cas9 T-DNA cassette. Floral dip was used to transfer this cassette into C. hirsuta by Agrobacterium tumefaciensmediated transformation. T1 transformants were selected as Basta-resistant, the sgRNA flanking region was PCR-amplified, Sanger-sequenced and analyzed for induced mutations using http://yosttools.genetics.utah.edu/PolyPeakParser to parse double peaks into wildtype and mutant allele sequences. A single T-DNA insertion line contained a nucleotide insertion at position $343 \mathrm{bp}$ from the first Met that converted the GAC triplet into GAAC, introducing a frameshift. T2 progeny of this plant were PCR genotyped with M13F and sg1 primers to identify and discard transgenic plants, then the transgene-free plants were screened for the expected indehiscent fruit phenotype. We confirmed that indehiscent 
plants were homozygous for the nucleotide insertion described above using Ta-sensitive PCR primers (chind-wt-F, chind-mutant-F and chind-qRT-R) and HiDi DNA polymerase. The allele was named C. hirsuta ind-1.

Construction of transgenes. pAtIND::AtIND:EYFP and pAtIND:GR-pOp6:AtIND were a kind gift from L. Ostergaard (Li et al., 2018) and gAtFUL:GFP from G. Angenent (Urbanus et al., 2009). MultiSite Gateway cloning was used to generate all other constructs unless indicated. pChIND::ChIND:Venus: 1,885 bp of untranscribed IND promoter sequence, corresponding to the entire intergenic region, was amplified from genomic $C$. hirsuta DNA with PCR primers pChIND-attB4-F and pChIND-attB1r-R, and subcloned into pGEM1R4_easy entry vector; 585 bp of transcribed IND sequence from the first Met and excluding the STOP codon was amplified from genomic $C$. hirsuta DNA with PCR primers ChIND-attB1-F and ChIND-attB2-R, and subcloned into pGEM221_easy entry vector; these entry vectors were recombined with the p4gly-vYFP-3AT_2R3 entry vector to generate pChIND::ChIND:Venus in the pGREENII125 binary vector that contains norflurazon selection (Galinha et al., 2007; Prasad et al., 2011). pChIND::3xVenus: pChIND_1R4 and 3x-vYFP_221 entry vectors were recombined to generate pChIND::3xVenus in the pGREENII125 binary vector. pChIND-UTR::3xVenus: 1,969 bp sequence including $1,885 \mathrm{bp}$ IND promoter and an additional $84 \mathrm{bp}$ of predicted 5'UTR that corresponds to the first 28 amino acids shown in Figure S2B, was amplified from genomic $C$. hirsuta DNA with PCR primers pChIND-attB4-F and pChIND-attB1r-R-UTR, subcloned into pGEM1R4_easy entry vector, and recombined with 3x-vYFP_221 entry vector to generate pChIND-UTR::3xVenus in the pFANTASTIC (pFAN) binary vector that contains a pOLE1:OLE1:RFP cassette for seed fluorescence selection. pFAN is a 
modified version of pPZP200 containing the R4-R3 MultiSite Gateway cassette from pGREENII125. p35S::ChIND: 585 bp of transcribed IND sequence from the first Met and including the STOP codon was amplified from genomic C. hirsuta DNA with PCR primers (ChIND-F-XhoI and ChIND-R-BamHI), subcloned into pART7 using $\underline{X h o}$ I and BamHI restriction enzymes to generate p35S:ChIND-NosT, and transferred as a NcoI fragment into the binary vector pGREENII125

pChFUL::ChFUL:Venus: 6800 bp of $F U L$ promoter sequence was amplified from genomic $C$. hirsuta DNA with PCR primers pChFUL-attB4-F and pChFUL-attB1r-R, and subcloned into pGEM1R4_easy entry vector; 3400 bp of FUL gene including 5'UTR but excluding the STOP codon was amplified from genomic $C$. hirsuta DNA with PCR primers gAtFUL-attB1-F and gChFUL-attB1-R, and subcloned into pGEM221_easy entry vector; these entry vectors were recombined with the p4gly-vYFP-3AT_2R3 entry vector to generate pChFUL::ChFUL:Venus in pFAN. pChFUL::Gus: pChFUL_1R4 and GUS_221 entry vectors were recombined to generate pChFUL::Gus in the pGREENII125 binary vector. pAtFUL::gAtFUL:Venus: 1893 bp of $F U L$ promoter sequence was amplified from gFUL:GFP (de Folter et al., 2007) with PCR primers pAtFUL-attB4-F and pAtFULattB1r-R, and subcloned into pGEM1R4_easy entry vector; 3400 bp of FUL gene including 5'UTR but excluding the STOP codon was amplified from genomic A. thaliana L.er DNA with PCR primers gAtFUL-attB1-F and gAtFUL-attB2-R, and subcloned into pGEM221_easy entry vector; these entry vectors were recombined with the p4gly-vYFP3AT_2R3 entry vector to generate pAtFUL::AtFUL:Venus in pFAN and pGREENII125 binary vectors. pChFUL::gAtFUL:Venus: pChFUL_1R4 and AtFUL_221 entry vectors were recombined with p4gly-vYFP-3AT_2R3 to generate pChFUL::AtFUL:Venus in 
pFAN and pGREENII125 binary vectors. pAtFUL::gChFUL:Venus: pAtFUL_1R4 and ChFUL_221 entry vectors were recombined with p4gly-vYFP-3AT_2R3 to generate pAtFUL::ChFUL:Venus in pFAN and pGREENII125 binary vectors.

pChALC::ChALC:Venus: 720 bp of untranscribed $A L C$ promoter sequence, corresponding to the entire intergenic region, was amplified from genomic C. hirsuta DNA with PCR primers AG119-pChALC-attB4-F and AG120-pChALC-attB1r-R, and subcloned into pGEM1R4_easy entry vector; $633 \mathrm{bp}$ of transcribed $A L C$ sequence from the first Met and excluding the STOP codon was amplified from genomic $C$. hirsuta DNA with PCR primers (AG129-ChALC-attB1-F and AG130-ChALC-attB2-R) and subcloned into pGEM221_easy entry vector (cChALC_221); these entry vectors were recombined with the p4gly-vYFP-3AT_2R3 entry vector to generate pChALC::ChALC:Venus in the pFAN binary vector that contains seed-coat-RFP fluorescence selection marker.

All plasmids are listed in Table S2. Floral dip was used to transfer plasmids into $C$. hirsuta and A. thaliana genotypes by Agrobacterium tumefaciens-mediated transformation. Transgene copy number was determined by g-Count (IDna Genetics Ltd) and 5-15 single copy lines were analyzed for each transgene to determine consensus phenotypes and expression patterns for each transgene.

Virus Induced Gene Silencing (VIGS). pTRV2-ChFUL-ChPDS was constructed by cloning a $421 \mathrm{bp}$ fragment containing part of the $\mathrm{K}$ domain, the $\mathrm{C}$ domain, and part of the 3'UTR of C. hirsuta FUL, that was amplified from fruit cDNA using primers ChFUL-F and ChFUL-R, and cloned into pTRV2-ChPDS via EcoRI and XbaI restriction sites. pTRV2-ChPDS was constructed by cloning a 471 bp fragment of $C$. hirsuta PHYTOENE DESATURASE ChPDS (CARHR220290.1), that was amplified using primers ChPDS-F 
and ChPDS-R, into pTRV2 via XbaI and KpnI restriction sites. Both pTRV2-ChFULChPDS and pTRV2-ChPDS were transformed into Agrobacterium tumefaciens GV3101 and VIGS was performed as previously described (Kramer et al., 2007) by infiltrating young C. hirsuta leaves.

Histology. Plastic embedding and Toluidine blue O (TBO) staining of fruit tissue was similar to (Neumann and Hay, 2019). Fruit were fixed with 1\% gluturaldehyde (Agar Scientific) and 4\% formaldehyde (Fisher Scientific) in $0.05 \mathrm{M}$ phosphate buffer ( $\mathrm{pH} 7.2$ ) for 15 minutes and then left shaking at $4^{\circ} \mathrm{C}$ overnight. After washing with $0.5 \mathrm{M}$ phosphate buffer ( $\mathrm{pH}$ 7.2), samples were dehydrated through an ethanol series and gradually embedded in Technovit 7100 resin at room temperature. The resin was polymerized and embedded with hardener I and hardener II according to manufacturer's instructions and epoxy glued to rubber stubs. Semi-thin sections $(5 \mu \mathrm{m})$ were collected on glass slides, stained with $0.05 \%$ TBO in $0.1 \mathrm{M}$ phosphate buffer ( $\mathrm{pH} 5.7$ ), rinsed with $\mathrm{dH}_{2} \mathrm{O}$ and mounted in DPX Mounting Medium (Agar Scientific). Images were taken with a Zeiss Axio Imager.

Propidium iodide $(5 \mathrm{mg} / \mathrm{mL})$ staining was performed with either whole fruit segments for $10 \mathrm{~min}$, or with thick vibratome-cut sections $(150 \mu \mathrm{m})$ for $5 \mathrm{~min}$, after fixing in $2 \%$ paraformaldehyde and embedding in $10 \%$ low melt agarose. Samples were immediately imaged with a Leica SP8 upright confocal microscope.

Staining with the dead cell marker Sytox Blue (S34857, Thermo Fisher) was performed by incubating fruit in $1 \mu \mathrm{M}$ aqueous Sytox Blue in Eppendorf tubes for $6 \mathrm{~h}$ at room temperature in the dark. Fruits were imaged in water using a Zeiss Axio Imager with 
a DAPI filter. Nuclear sytox blue stain could be distinguished from cell wall lignin autofluorescence.

For phloroglucinol staining, fruit were fixed in $2 \%$ paraformaldehyde, embedded in $10 \%$ low melt agarose, cut into thick vibratome sections $(150 \mu \mathrm{m})$ and stained with $2 \%$ phloroglucinol in $95 \%$ ethanol for $10 \mathrm{~min}$ at room temperature, then acidified by transferring to $10 \mathrm{M} \mathrm{HCl}$ for $1 \mathrm{~min}$, mounted and imaged immediately in $1 \mathrm{M} \mathrm{HCl}$ using a Zeiss Axio Imager with differential interference contrast.

$\beta$-Glucuronidase (GUS) staining of whole fruit was performed as previously described (Lilley et al., 2012). After staining at $37^{\circ} \mathrm{C}$ overnight, fruit were fixed with either FAA (50\% ethanol, 3.7\% formaldehyde, and 5\% acetic acid) or $2.5 \%$ gluturaldehyde in phosphate buffered saline for $60 \mathrm{~min}$. After repeated washing with phosphate buffered saline, samples were dehydrated through an ethanol series into histoclear, embedded in Paraplast Plus, and 8-10 $\mu \mathrm{m}$ sections were deparaffinized and imaged using a Zeiss Axio Imager with differential interference contrast.

Dexamethasone treatments. Dexamethasone (Sigma-Aldrich) solutions of $5 \mu \mathrm{M}, 25 \mu \mathrm{M}$ and $100 \mu \mathrm{M}$ were freshly prepared from a $10 \mathrm{mM}$ aqueous stock with $0.015 \%$ Silwet L77. Mock solutions contained $0.015 \%$ Silwet L-77 in water. Solutions were sprayed directly on $C$. hirsuta inflorescences just after bolting every 2 days over 2 weeks until the oldest fruit reached stage $17 \mathrm{~b}$.

Scanning Electron Microscopy (SEM). Fruit were fixed, dehydrated, critical point dried, sputter coated, and imaged with either a Zeiss Supra 40VP or a JSM-5510 (Joel) microscope as previously described (Neumann and Hay, 2019). 
Confocal laser scanning microscopy (CLSM). A Leica SP8 upright CLSM with 20x and 40x objectives was used with these excitation wavelengths: Venus and EYFP (514 nm with 519-569 nm bandpass filter), tdTomato (554 nm with 600-680 nm bandpass filter), PI (488 $\mathrm{nm}$ with $628-735 \mathrm{~nm}$ bandpass filter), chlorophyll autofluorescence (514 with 628-735 nm bandpass filter).

Time-lapse CLSM and quantitative image analysis. Time-lapse imaging was performed with C. hirsuta $p U B Q 10:: a c y l: t d T$ transgenic plants (gift from Tsiantis lab, modified from (Segonzac et al., 2012)). A reference point was gently marked in the centre of each fruit with permanent marker before and after imaging. Fruit were mounted in water with the valve margin facing the cover slip and imaged at $0 \mathrm{~h}$ (stage 15), $48 \mathrm{~h}$ (stage 16), $96 \mathrm{~h}$ (stage 17a) and $168 \mathrm{~h}$ (stage $17 \mathrm{~b}$ ). Fruit stages were estimated by fruit length: stage $15=5-9 \mathrm{~mm}$, stage $16=10-16 \mathrm{~mm}$, stage $17=17-20 \mathrm{~mm}$. Fruit remained attached to the plant, and plants were returned to the greenhouse between imaging. Image stacks were acquired at $512 \times 512$ pixels without averaging, with 0.5-0.8 $\mu \mathrm{m}$ distance in Z-dimension, and were analyzed using MorphoGraphX software (Barbier de Reuille et al., 2015). Multiple image stacks were required to capture later time points and these stacks were stitched using MorphoGraphX. After cells were segmented, parent relations between successive stages were determined manually and used to quantify cell area extension. Heat maps are displayed on the second of two time points. Cells were assigned tissue identities using the cell distance process with filtering based on cell morphology, and these identities were exported as parent labels to calculate area extension in organ-aligned directions in each tissue (Zhang et al., 2020).Two replicate time-lapse series were acquired from fruit on different plants in a single experiment, and progression through developmental stages to 
explosion was compared with non-imaged fruit to show a negligible effect of imaging on fruit development.

Fruit measurements. Digital photographs of fruit (Nikon camera) were measured from stigma tip to gynophore base with the straight-line tool in FiJi (Schindelin et al., 2012).

Quantitative RT-PCR analysis. C. hirsuta tissue samples were collected and immediately frozen in liquid nitrogen and stored at $-80^{\circ} \mathrm{C}$ before processing. Total RNA was extracted using the Spectrum Plant Total RNA Kit (Sigma-Aldrich), treated with DNaseI on columns (Sigma-Aldrich), and converted into cDNA using SuperScript VILO (Thermo Fisher Scientific) and an oligo-dT primer. Quantitative PCR was performed in triplicate using Power SYBR Green Master Mix (Thermo Fisher Scientific) in a QuantStudio Real-Time PCR System (Applied Biosystems). Primer efficiency and gene expression were quantified using the standard curve method as previously described (Pfaffl, 2001). Primers were designed using the QuantPrime program and checked for specificity by BLAST to the $C$. hirsuta genome. Gene expression was normalized against the reference gene CLATHRIN/AP2M and estimated as fold change relative to a control sample, with error calculated using $\Delta \mathrm{Ct}$ values of biological replicates.

RNA-seq analysis. Fruits of $C$. hirsuta wild type, ind- 1 and ful- 1 were harvested at stage $17 \mathrm{~b}$ and seeds and septum tissue were removed. Total RNA was extracted from $100 \mathrm{mg}$ of whole seedling tissue using the Spectrum Plant Total RNA Kit (Sigma, STRN50) and $1 \mu 1$ of eluted RNA was used for complementary DNA (cDNA) synthesis using SuperScript Vilo (Invitrogene, 11754-050). RNA quality was assessed by Bioanalyser Nanochip (Agilent, Santa Clara, U.S.A.), and libraries quantified by Qubit (ThermoFisher, Waltham, U.S.A.). Libraries were prepared according to NEBNext Ultra ${ }^{\mathrm{TM}}$ Directional RNA Library 
Prep Kit for Illumina (New England Biolabs, Ipswich, U.S.A.) followed by single end sequencing on a HiSeq3000 to produce 2-3 Gb data per sample. RNA-sequencing reads were aligned against the $C$. hirsuta genome (Gan et al., 2016) and a cut-off of five reads in every sample that uniquely mapped to annotated genes was used as criteria for further analysis, giving a total of 22981 genes. We used the DESeq2 Bioconductor package (Anders and Huber, 2010) for all following analyses. Based on a principal component analysis of the log-transform of all samples, one wild-type replicate was removed (Fig. S7). We fitted a linear model to the genes to estimate the effect of each genotype (wild-type, ind-1, ful-1) on each gene. We then clustered the normalized, three-dimensional vectors into 8 different clusters (Fig. S7, Table S3). The number of clusters was selected based on the total variance within the clusters. Differentially expressed genes were identified between wild type and ind-1, and wild type and ful-1 (Tables S4, S7). Then we applied a contrast analysis to obtain the differentially expressed genes in selected clusters (Tables S5, S8). We included genes with an absolute $\operatorname{logFC}$ higher than 1 and adjusted p-value lower than 0.05. A. thaliana othologs were retrieved for all C. hirsuta gene identifiers (Gan et al., 2016) and used with DAVID (Huang et al Nature 2009) for gene ontology analysis.

Primers. All primer sequences are listed in supplementary Table S1.

\section{Acknowledgements}

We thank A. Emonet for comments, W. Faigl, R. Berndtgen, S. Strauss, R. Lympouridou and S. Pophaly for valuable assistance, and L. Ostergaard and G. Angenent for materials.

\section{Competing interests}

No competing interests declared. 


\section{Author contributions}

A.G. and A.H. designed experiments; A.G., P.S., L.N., M.P-A. and H.H. performed research; A.G., P.S., R.C-M., X.G., L.R-L. and M.A. analyzed data; A.H. designed and directed the study and wrote the paper with A.G.; all authors commented on the article.

\section{Funding}

This work was supported by a Humboldt postdoctoral research fellowship to A.G.; a

Newton Abraham scholarship to P.S.; and a Max Planck Society W2 Minerva programme fellowship to A.H.

\section{Data availability}

ENA sequence read depository. 


\section{References}

Anders, S. and Huber, W. (2010). Differential expression analysis for sequence count data. Genome Biol 11, R106.

Arnaud, N., Girin, T., Sorefan, K., Fuentes, S., Wood, T. A., Lawrenson, T., Sablowski, R. and Ostergaard, L. (2010). Gibberellins control fruit patterning in Arabidopsis thaliana. Genes Dev 24, 2127-2132.

Bailey, P. C., Martin, C., Toledo-Ortiz, G., Quail, P. H., Huq, E., Heim, M. A., Jakoby, M., Werber, M. and Weisshaar, B. (2003). Update on the basic helixloop-helix transcription factor gene family in Arabidopsis thaliana. Plant Cell 15, 2497-2502.

Ballester, P. and Ferrandiz, C. (2017). Shattering fruits: variations on a dehiscent theme. Curr Opin Plant Biol 35, 68-75.

Barbier de Reuille, P., Routier-Kierzkowska, A. L., Kierzkowski, D., Bassel, G. W., Schupbach, T., Tauriello, G., Bajpai, N., Strauss, S., Weber, A., Kiss, A., et al. (2015). MorphoGraphX: A platform for quantifying morphogenesis in 4D. Elife 4:e05864.

Brazel, A. J. and O'Maoileidigh, D. S. (2019). Photosynthetic activity of reproductive organs. J Exp Bot 70, 1737-1754.

Carretero-Paulet, L., Galstyan, A., Roig-Villanova, I., Martinez-Garcia, J. F., Bilbao-Castro, J. R. and Robertson, D. L. (2010). Genome-wide classification and evolutionary analysis of the bHLH family of transcription factors in Arabidopsis, poplar, rice, moss, and algae. Plant Physiol 153, 1398-1412.

Cox, C. M. and Swain, S. M. (2006). Localised and non-localised promotion of fruit development by seeds in Arabidopsis. Funct Plant Biol 33, 1-8.

de Folter, S., Urbanus, S. L., van Zuijlen, L. G., Kaufmann, K. and Angenent, G. C. (2007). Tagging of MADS domain proteins for chromatin immunoprecipitation. BMC plant biology 7, 47.

Dinneny, J. R. and Yanofsky, M. F. (2005). Drawing lines and borders: how the dehiscent fruit of Arabidopsis is patterned. Bioessays 27, 42-49.

Dong, Y., Jantzen, F., Stacey, N., Langowski, L., Moubayidin, L., Simura, J., Ljung, K. and Ostergaard, L. (2019). Regulatory Diversification of INDEHISCENT in the Capsella Genus Directs Variation in Fruit Morphology. Curr Biol 29, 10381046 e1034.

Dong, Y., Majda, M., Simura, J., Horvath, R., Srivastava, A. K., Langowski, L., Eldridge, T., Stacey, N., Slotte, T., Sadanandom, A., et al. (2020). HEARTBREAK Controls Post-translational Modification of INDEHISCENT to Regulate Fruit Morphology in Capsella. Curr Biol 30, 3880-3888 e3885.

Ferrandiz, C., Gu, Q., Martienssen, R. and Yanofsky, M. F. (2000a). Redundant regulation of meristem identity and plant architecture by FRUITFULL, APETALA1 and CAULIFLOWER. Development 127, 725-734.

Ferrandiz, C., Liljegren, S. J. and Yanofsky, M. F. (2000b). Negative regulation of the SHATTERPROOF genes by FRUITFULL during Arabidopsis fruit development. Science 289, 436-438. 
Galinha, C., Hofhuis, H., Luijten, M., Willemsen, V., Blilou, I., Heidstra, R. and Scheres, B. (2007). PLETHORA proteins as dose-dependent master regulators of Arabidopsis root development. Nature 449, 1053-1057.

Gallego-Bartolome, J., Minguet, E. G., Marin, J. A., Prat, S., Blazquez, M. A. and Alabadi, D. (2010). Transcriptional diversification and functional conservation between DELLA proteins in Arabidopsis. Mol Biol Evol 27, 1247-1256.

Gan, X., Hay, A., Kwantes, M., Haberer, G., Hallab, A., Ioio, R. D., Hofhuis, H., Pieper, B., Cartolano, M., Neumann, U., et al. (2016). The Cardamine hirsuta genome offers insight into the evolution of morphological diversity. Nat Plants $\mathbf{2}$, 16167.

Girin, T., Paicu, T., Stephenson, P., Fuentes, S., Korner, E., O'Brien, M., Sorefan, K., Wood, T. A., Balanza, V., Ferrandiz, C., et al. (2011). INDEHISCENT and SPATULA interact to specify carpel and valve margin tissue and thus promote seed dispersal in Arabidopsis. Plant Cell 23, 3641-3653.

Girin, T., Stephenson, P., Goldsack, C. M., Kempin, S. A., Perez, A., Pires, N., Sparrow, P. A., Wood, T. A., Yanofsky, M. F. and Ostergaard, L. (2010). Brassicaceae INDEHISCENT genes specify valve margin cell fate and repress replum formation. Plant $J \mathbf{6 3}, 329-338$.

Groszmann, M., Paicu, T., Alvarez, J. P., Swain, S. M. and Smyth, D. R. (2011). SPATULA and ALCATRAZ, are partially redundant, functionally diverging bHLH genes required for Arabidopsis gynoecium and fruit development. Plant $J$ 68, 816-829.

Gu, Q., Ferrandiz, C., Yanofsky, M. F. and Martienssen, R. (1998). The FRUITFULL MADS-box gene mediates cell differentiation during Arabidopsis fruit development. Development 125, 1509-1517.

Hay, A. and Tsiantis, M. (2006). The genetic basis for differences in leaf form between Arabidopsis thaliana and its wild relative Cardamine hirsuta. Nat Genet 38, 942947.

Heim, M. A., Jakoby, M., Werber, M., Martin, C., Weisshaar, B. and Bailey, P. C. (2003). The basic helix-loop-helix transcription factor family in plants: a genomewide study of protein structure and functional diversity. Mol Biol Evol 20, 735 747.

Hofhuis, H., Moulton, D., Lessinnes, T., Routier-Kierzkowska, A. L., Bomphrey, R. J., Mosca, G., Reinhardt, H., Sarchet, P., Gan, X., Tsiantis, M., et al. (2016). Morphomechanical innovation drives explosive seed dispersal. Cell 166, 222-233.

Homann, O. R., Dea, J., Noble, S. M. and Johnson, A. D. (2009). A phenotypic profile of the Candida albicans regulatory network. Plos Genet 5, e1000783.

Hyun, Y., Kim, J., Cho, S. W., Choi, Y., Kim, J. S. and Coupland, G. (2015). Sitedirected mutagenesis in Arabidopsis thaliana using dividing tissue-targeted RGEN of the CRISPR/Cas system to generate heritable null alleles. Planta 241, 271-284.

Kay, P., Groszmann, M., Ross, J. J., Parish, R. W. and Swain, S. M. (2013). Modifications of a conserved regulatory network involving INDEHISCENT controls multiple aspects of reproductive tissue development in Arabidopsis. New Phytol 197, 73-87. 
Kokko, H. and Lopez-Sepulcre, A. (2006). From individual dispersal to species ranges: perspectives for a changing world. Science 313, 789-791.

Kramer, E. M., Holappa, L., Gould, B., Jaramillo, M. A., Setnikov, D. and Santiago, P. M. (2007). Elaboration of B gene function to include the identity of novel floral organs in the lower eudicot Aquilegia. Plant Cell 19, 750-766.

Lenser, T. and Theissen, G. (2013). Conservation of fruit dehiscence pathways between Lepidium campestre and Arabidopsis thaliana sheds light on the regulation of INDEHISCENT. Plant J 76, 545-556.

Li, X. R., Deb, J., Kumar, S. V. and Ostergaard, L. (2018). Temperature modulates tissue-specification program to control fruit dehiscence in Brassicaceae. $\mathrm{Mol}$ Plant 11, 598-606.

Li, X. R., Vroomans, R. M. A., Fox, S., Grieneisen, V. A., Ostergaard, L. and Maree, A. F. M. (2019). Systems biology approach pinpoints minimum requirements for auxin distribution during fruit opening. Mol Plant 12, 863-878.

Liljegren, S. J., Ditta, G. S., Eshed, Y., Savidge, B., Bowman, J. L. and Yanofsky, M. F. (2000). SHATTERPROOF MADS-box genes control seed dispersal in Arabidopsis. Nature 404, 766-770.

Liljegren, S. J., Roeder, A. H., Kempin, S. A., Gremski, K., Ostergaard, L., Guimil, S., Reyes, D. K. and Yanofsky, M. F. (2004). Control of fruit patterning in Arabidopsis by INDEHISCENT. Cell 116, 843-853.

Lilley, J. L., Gee, C. W., Sairanen, I., Ljung, K. and Nemhauser, J. L. (2012). An endogenous carbon-sensing pathway triggers increased auxin flux and hypocotyl elongation. Plant Physiol 160, 2261-2270.

Mitsuda, N. and Ohme-Takagi, M. (2008). NAC transcription factors NST1 and NST3 regulate pod shattering in a partially redundant manner by promoting secondary wall formation after the establishment of tissue identity. Plant J 56, 768-778.

Neumann, U. and Hay, A. (2019). Seed coat development in explosively dispersed seeds of Cardamine hirsuta. Ann Bot.

Ogawa, M., Kay, P., Wilson, S. and Swain, S. M. (2009). ARABIDOPSIS DEHISCENCE ZONE POLYGALACTURONASE1 (ADPG1), ADPG2, and QUARTET2 are Polygalacturonases required for cell separation during reproductive development in Arabidopsis. Plant Cell 21, 216-233.

Pfaffl, M. W. (2001). A new mathematical model for relative quantification in real-time RT-PCR. Nucleic Acids Res 29, e45.

Prasad, K., Grigg, S. P., Barkoulas, M., Yadav, R. K., Sanchez-Perez, G. F., Pinon, V., Blilou, I., Hofhuis, H., Dhonukshe, P., Galinha, C., et al. (2011). Arabidopsis PLETHORA transcription factors control phyllotaxis. Curr Biol 21, 1123-1128.

Rajani, S. and Sundaresan, V. (2001). The Arabidopsis myc/bHLH gene ALCATRAZ enables cell separation in fruit dehiscence. Curr Biol 11, 1914-1922.

Ripoll, J. J., Bailey, L. J., Mai, Q. A., Wu, S. L., Hon, C. T., Chapman, E. J., Ditta, G. S., Estelle, M. and Yanofsky, M. F. (2015). microRNA regulation of fruit growth. Nature Plants $\mathbf{1}$.

Ripoll, J. J., Zhu, M., Brocke, S., Hon, C. T., Yanofsky, M. F., Boudaoud, A. and Roeder, A. H. K. (2019). Growth dynamics of the Arabidopsis fruit is mediated by cell expansion. Proc Natl Acad Sci U S A 116, 25333-25342. 
Roeder, A. H., Ferrandiz, C. and Yanofsky, M. F. (2003). The role of the REPLUMLESS homeodomain protein in patterning the Arabidopsis fruit. Curr Biol 13, 1630-1635.

Schindelin, J., Arganda-Carreras, I., Frise, E., Kaynig, V., Longair, M., Pietzsch, T., Preibisch, S., Rueden, C., Saalfeld, S., Schmid, B., et al. (2012). Fiji: an opensource platform for biological-image analysis. Nat Methods 9, 676-682.

Segonzac, C., Nimchuk, Z. L., Beck, M., Tarr, P. T., Robatzek, S., Meyerowitz, E. M. and Zipfel, C. (2012). The shoot apical meristem regulatory peptide CLV3 does not activate innate immunity. Plant Cell 24, 3186-3192.

Sorefan, K., Girin, T., Liljegren, S. J., Ljung, K., Robles, P., Galvan-Ampudia, C. S., Offringa, R., Friml, J., Yanofsky, M. F. and Ostergaard, L. (2009). A regulated auxin minimum is required for seed dispersal in Arabidopsis. Nature 459, 583-586.

Spence, J., Vercher, Y., Gates, P. and Harris, N. (1996). 'Pod shatter' in Arabidopsis thaliana, Brassica napus and B-juncea. J Microsc-Oxford 181, 195-203.

Toledo-Ortiz, G., Huq, E. and Quail, P. H. (2003). The Arabidopsis basic/helix-loophelix transcription factor family. Plant Cell 15, 1749-1770.

True, J. R. and Haag, E. S. (2001). Developmental system drift and flexibility in evolutionary trajectories. Evol Dev 3, 109-119.

Urbanus, S. L., de Folter, S., Shchennikova, A. V., Kaufmann, K., Immink, R. G. and Angenent, G. C. (2009). In planta localisation patterns of MADS domain proteins during floral development in Arabidopsis thaliana. BMC plant biology 9 , 5.

van Gelderen, K., van Rongen, M., Liu, A. A., Otten, A. and Offringa, R. (2016). An INDEHISCENT-controlled auxin response specifies the separation layer in early Arabidopsis fruit. Mol Plant 9, 857-869.

Wotton, K. R., Jimenez-Guri, E., Crombach, A., Janssens, H., Alcaine-Colet, A., Lemke, S., Schmidt-Ott, U. and Jaeger, J. (2015). Quantitative system drift compensates for altered maternal inputs to the gap gene network of the scuttle fly Megaselia abdita. Elife 4.

Zhang, Z., Runions, A., Mentink, R. A., Kierzkowski, D., Karady, M., Hashemi, B., Huijser, P., Strauss, S., Gan, X., Ljung, K., et al. (2020). A WOX/auxin biosynthesis module controls growth to shape leaf form. Curr Biol 30, 4857-4868 e4856. 


\section{Figure legends}
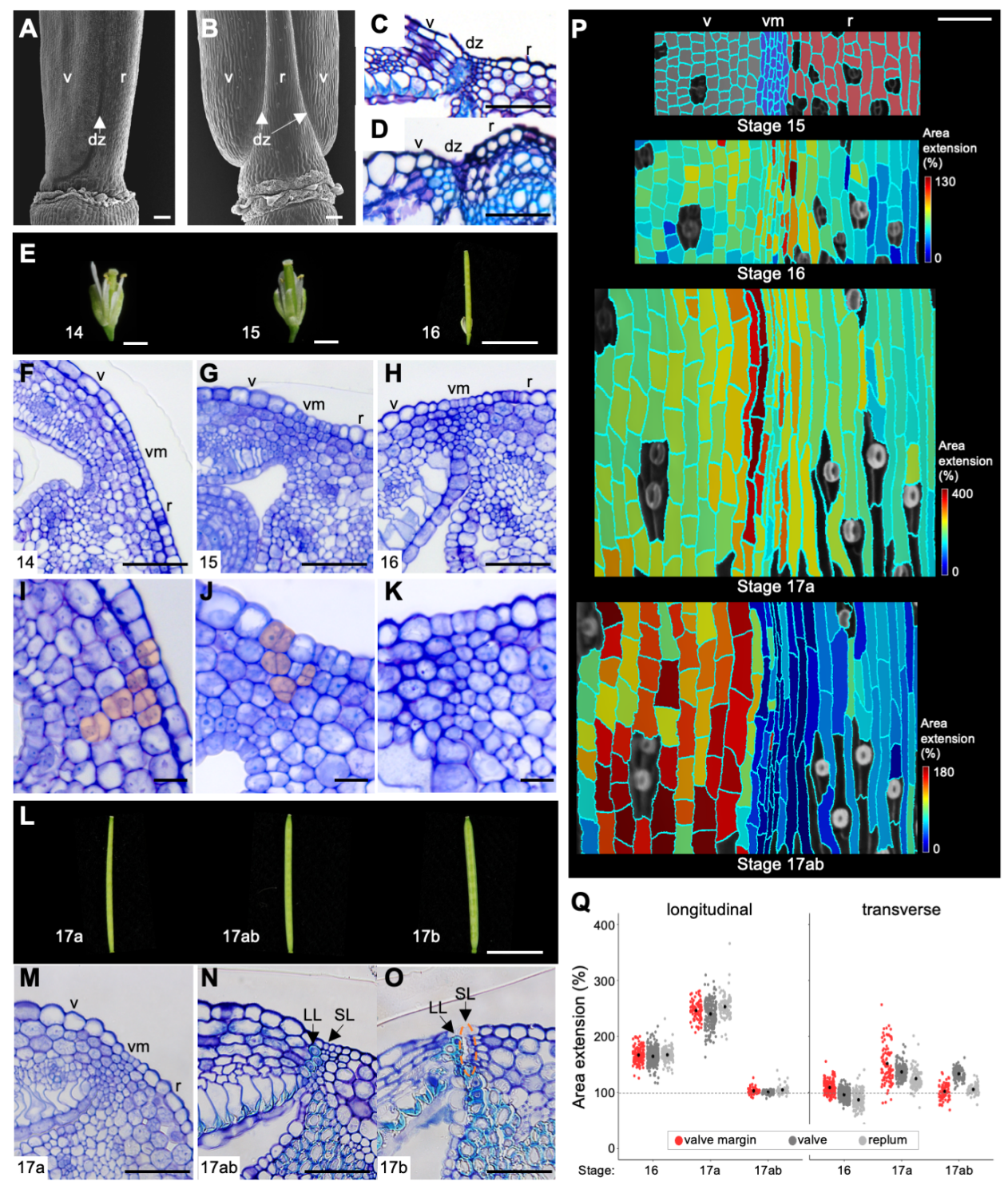

Figure 1.

Dehiscence

\section{zone}

development in $C$. hirsuta

fruit. (A-D)

C. hirsuta (A,

C) and $A$.

thaliana (B,

D) stage $17 \mathrm{~b}$

fruit base in

SEM (A-B)

and TBO-

stained

transverse

sections of

the

dehiscence

zone (C-D);

lignified cell

walls stain

cyan. (E-K)

C. hirsuta

stage 14 to 16

fruit $(\mathrm{E})$ and

TBO-stained

transverse

sections of

the valve

margin in

stage $14(\mathrm{~F}$,

I), $15(\mathrm{G}, \mathrm{J}), 16(\mathrm{H}, \mathrm{K})$ fruit; close-up views of the valve margin with recently divided cells indicated in orange (I-J). (L-O) C. hirsuta stage 17 a to $17 \mathrm{~b}$ fruit (L) and TBO-stained transverse sections of the valve margin in stage $17 \mathrm{a}(\mathrm{M}), 17 \mathrm{ab}(\mathrm{N}), 17 \mathrm{~b}(\mathrm{O})$ fruit; lignified cell walls stain cyan; dashed orange circle indicates separated cells. (P-Q) Cellular growth in a time-lapse series of $C$. hirsuta fruit during stages 15 to $17 \mathrm{ab}$. Heat maps indicate cell area extension (\%) between stages, each heat map scales the data between maximum and minimum values; fruit tissue types labelled at stage 15 (valve: grey, valve margin: blue, replum: red) (P). Cell area extension (\%) between stages in the longitudinal and transverse directions of the fruit, in valve margin (red), valve (dark grey) and replum (light grey); black dots indicate means; dashed line indicates no change in cell area; $n=1308$ cells (Q). Abbreviations: v, valve; r, replum; dz, dehiscence zone; vm, valve margin; LL, lignified layer; SL, separation layer. Scale bars: $100 \mu \mathrm{m}$ (A, B), $50 \mu \mathrm{m}$ (C, D, F-H, M-P), $10 \mu \mathrm{m}$ (I$\mathrm{K})$. 

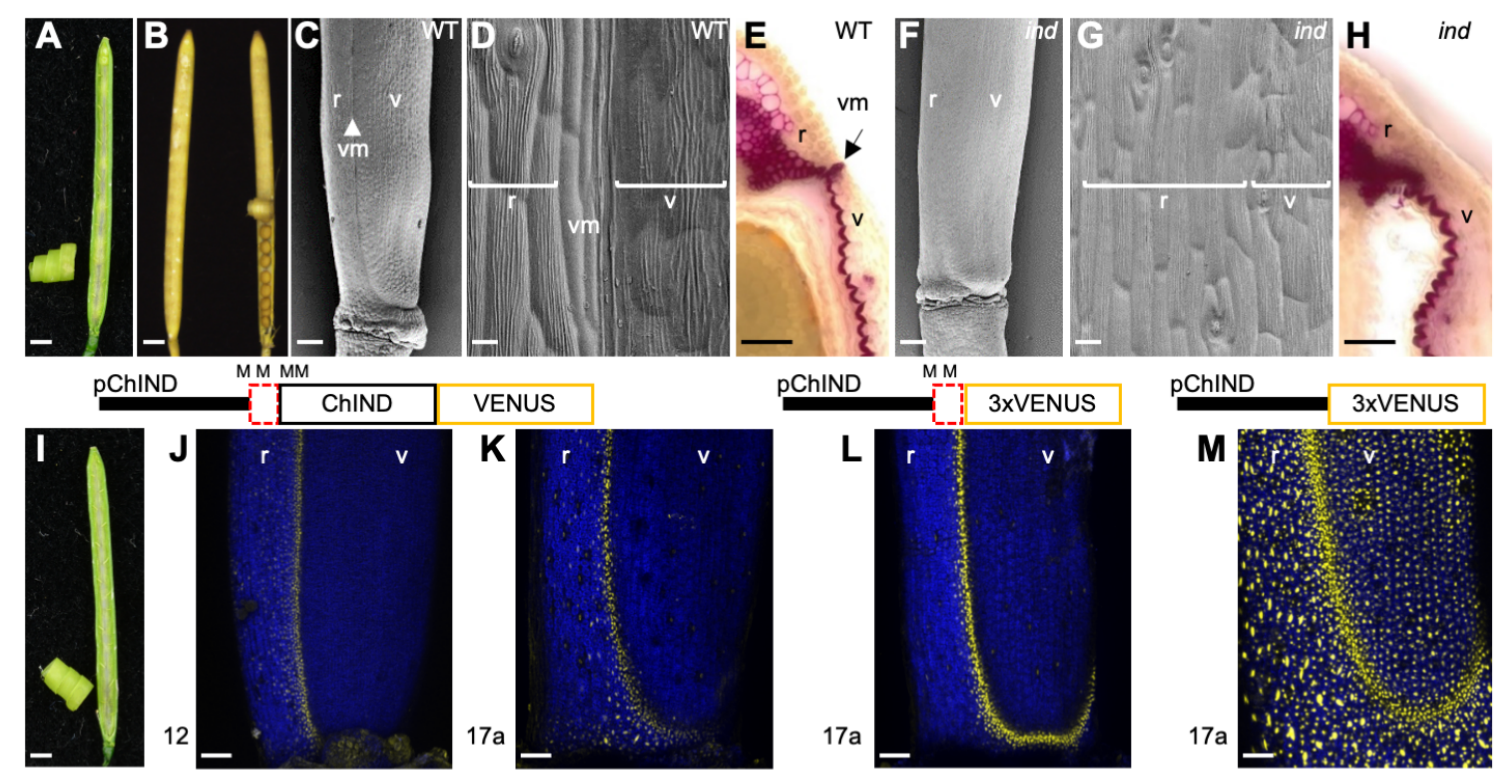

Figure 2. C. hirsuta ind mutant has non-explosive, indehiscent fruit. (A-B) C. hirsuta stage $17 \mathrm{~b}$ wild-type dehisced fruit and coiled valve (A), stage 18 ind-1 indehiscent fruit with coiled valve manually detached on right (B). (C-H) SEM (C-D, F-G) and phloroglucinol stained transverse sections $(\mathrm{E}, \mathrm{H})$ of stage 17ab C. hirsuta wild type and ind-1 fruit; lignified cell walls stain pink. (I-K) Fruit of ind-1 complemented with pChIND::ChIND:VENUS transgene (I), and CLSM of pChIND::ChIND:VENUS expression in stage $12(\mathrm{~J})$ and stage $17 \mathrm{a}(\mathrm{K})$ ind -1 fruit; $\mathrm{n}=11$ independent single insertion T2 lines. (L-M) CLSM of pChIND-UTR::3xVENUS (L) and pChIND::3xVENUS (M) transcriptional reporters in wild type stage $17 \mathrm{a}$ fruit; $\mathrm{n}=6$ independent $\mathrm{T} 1$ lines. Cartoons of each construct are shown above panels; $\mathrm{M}$ indicates predicted Met codons. Venus fluorescence (yellow), chlorophyll autofluorescence (blue). Scale bars: 1mm (A, B, I), $200 \mu \mathrm{m}(\mathrm{C}, \mathrm{F}), 10 \mu \mathrm{m}(\mathrm{D}, \mathrm{G}) 50 \mu \mathrm{m}(\mathrm{E}, \mathrm{H}, \mathrm{J}-\mathrm{M})$. Abbreviations: v, valve; r, replum; vm, valve margin. 

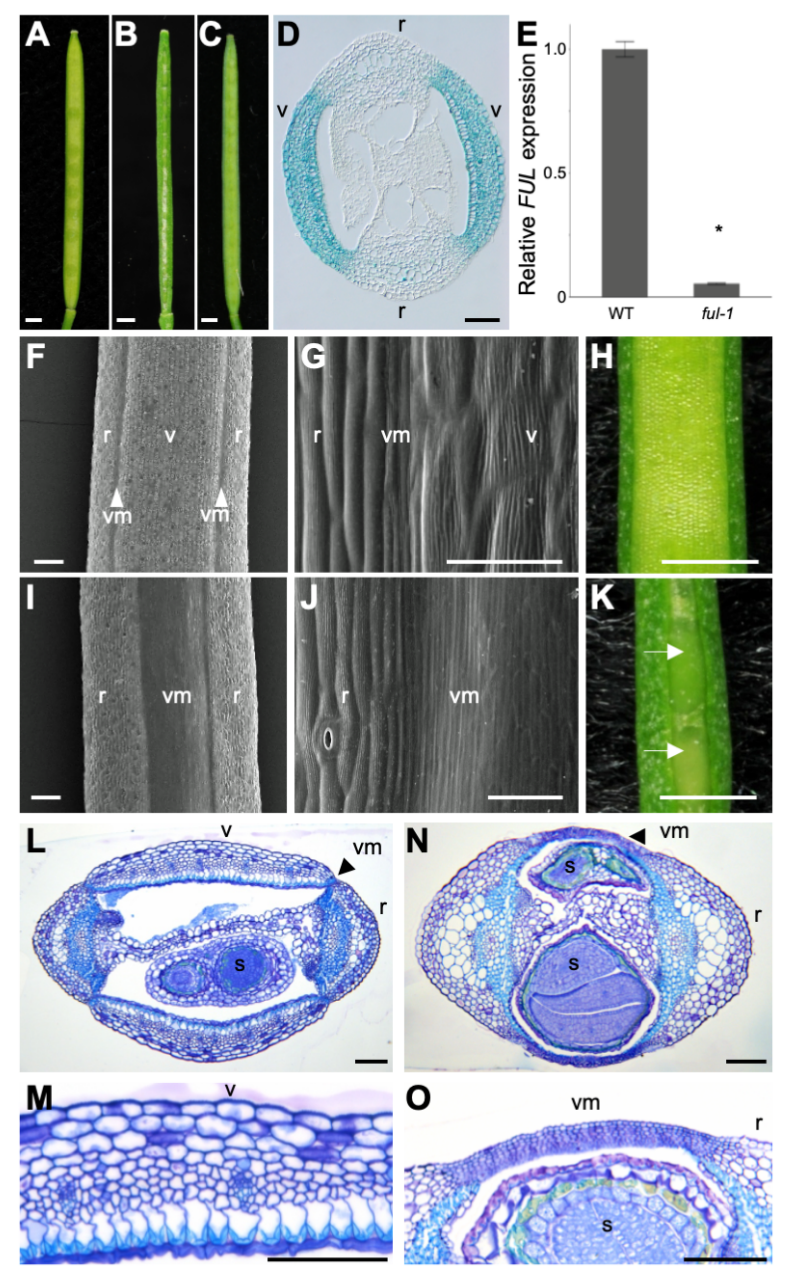

Figure 3. C. hirsuta ful mutant has

indehiscent fruits that lack valves. (A-C)

Fruit of C. hirsuta wild type (A), ful-1 (B)

and ful-1 complemented with pChFUL::ChFUL:VENUS transgene (C), $\mathrm{n}=11$ independent single insertion lines.

(D) Transverse section of $p C h F U L:: G U S$ fruit, blue colour indicates GUS expression in valves. (E) C. hirsuta FUL expression in wild-type and ful-1 stage 17 fruit, determined by quantitative RT-PCR, normalized to expression of the housekeeping gene CLATHRIN, and shown relative to wild type, bars represent mean \pm SEM of three biological replicates. Asterisk indicates statistically significant difference between wild type and ful-1 (P<0.05; Student's t-test). (F-K) Stage 17 fruit of wild type (F-H) and ful-1 (I-K). SEMs compare epidermal cell types between wild-type (FG) and $f u l-1$ (I-J) fruit. Arrows indicate visible seeds through the transparent tissue in $f u l$ $l$ fruit (K). (L-O) Toluidine Blue O-stained transverse sections of wild-type (L-M) and ful1 (N-O) fruit, close-up views of wild-type valve (M) and ectopic valve margin in ful-1(O); lignified cell walls stain cyan. Abbreviations: v, valve; r, replum; vm, valve margin; s, seed. Scale bar indicates $1 \mathrm{~mm}$ (A-C, H, K), $50 \mu \mathrm{m}$ (D, G, J), $100 \mu \mathrm{m}$ (F, I, L-O). 


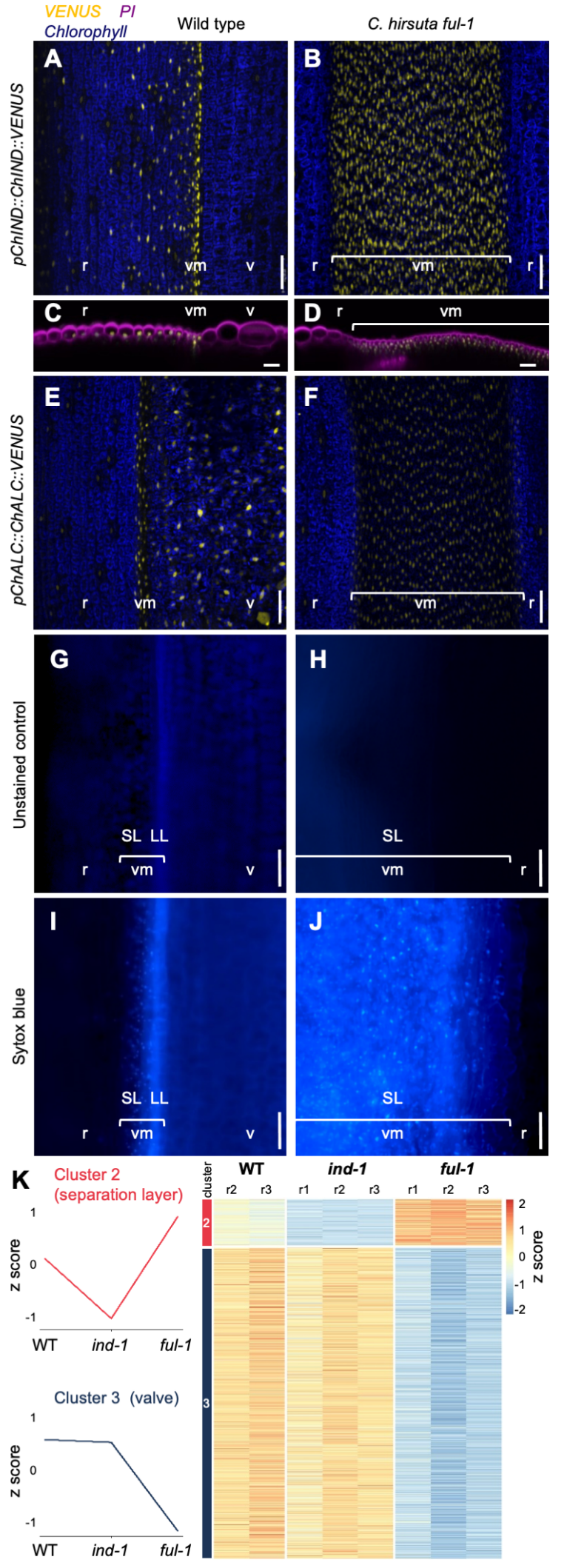

Figure 4. Homeotic conversion of valve to valve margin identity in $C$. hirsuta ful fruit. (A-F) CLSM of pChIND::cChIND:VENUS expression (yellow)

and pChALC::cChALC:VENUS expression (yellow) (E-F) in C. hirsuta stage 17a wildtype $(\mathrm{A}, \mathrm{C}, \mathrm{E})$ and $f u l-1(\mathrm{~B}, \mathrm{D}, \mathrm{F})$ fruit; chlorophyll autofluorescence (blue, A-B, EF); optical transverse slices through propidium iodide-stained Z-stacks (magenta, C-D). (G-J) Fluorescence micrographs of $C$. hirsuta stage 17 a wildtype $(\mathrm{G}, \mathrm{I})$ and $f u l-1(\mathrm{H}, \mathrm{J})$ fruit either unstained $(\mathrm{G}-\mathrm{H})$ or stained with Sytox blue cell death maker (I-J). (K) RNAseq analysis of C. hirsuta wild-type, ind- 1 and ful-1 stage $17 \mathrm{~b}$ fruit. Two gene expression clusters were selected and compared to differentially expressed genes between wild type and ind1 (cluster 2, 97 genes), or between wild type and ful-1 (cluster 3, 1367 genes); absolute $\log \mathrm{FC}>1$ and adjusted p-value $<0.05$. Heatmap indicates relative expression of each gene in each cluster, in each replicate sample of wild type, ind-1 and ful-1. Abbreviations: v, valve; r, replum; vm, valve margin; LL, lignified layer; SL, separation layer. Scale bars: $50 \mu \mathrm{m}(\mathrm{A}-\mathrm{J})$. 

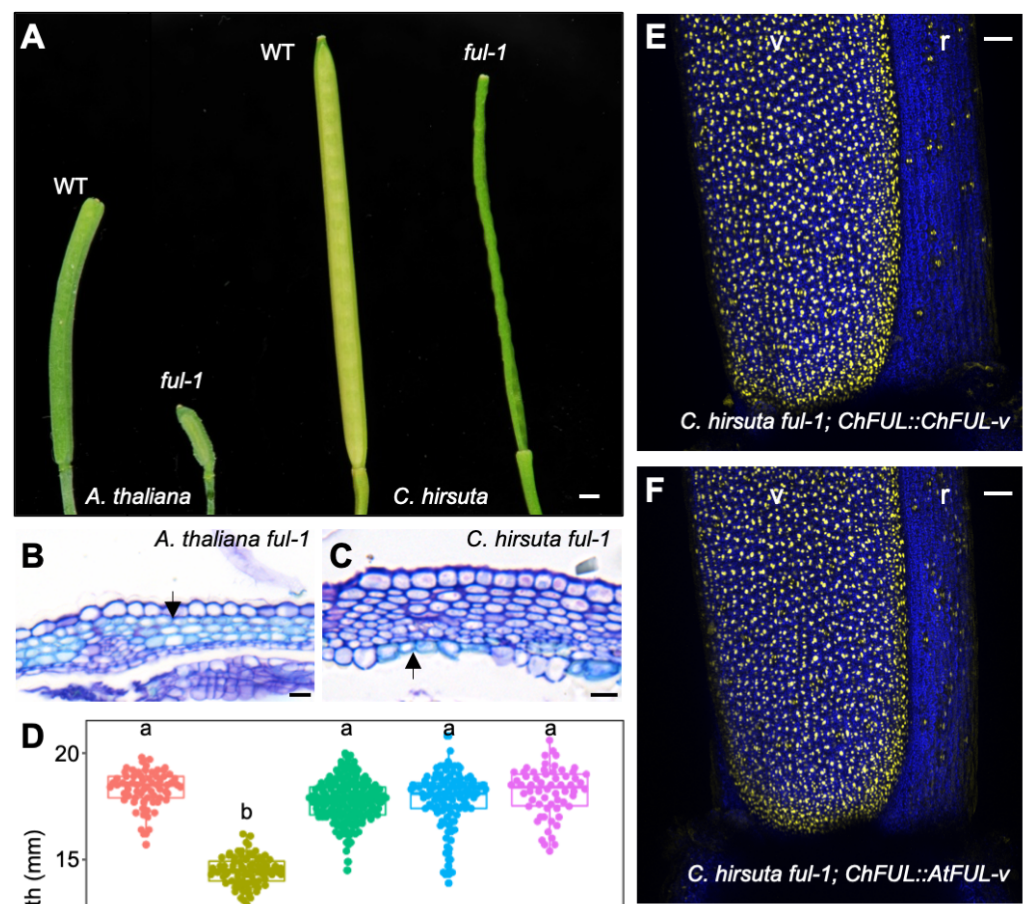

B

A. thaliana ful-1
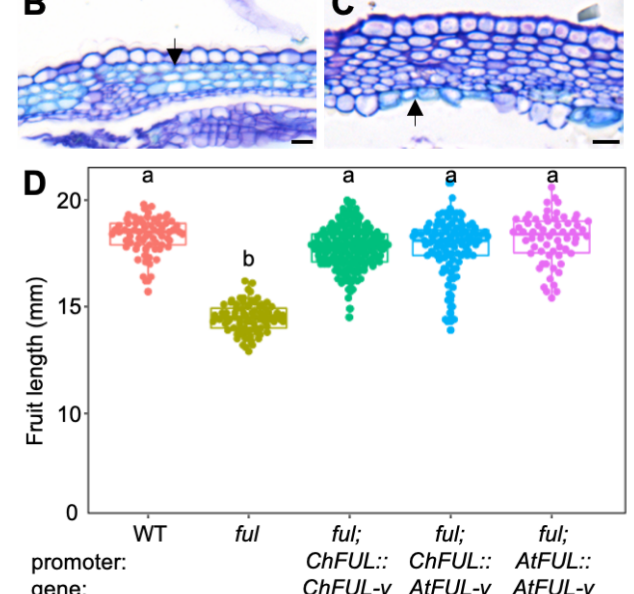

gene:

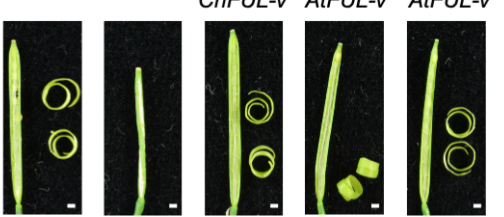

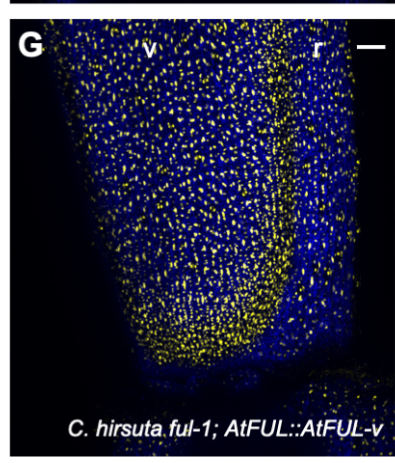

Figure 5. Conservation of $F U L$ function between $A$. thaliana and $C$. hirsuta. (A) Mature fruit of $A$. thaliana Landsberg erecta wild type, ful-1, and $C$. hirsuta wild type, ful-1. (BC) TBO-stained transverse sections of stage $17 \mathrm{~A}$. thaliana ful-1 (B) and $C$. hirsuta ful-1 (C), arrows indicate lignified cell walls stained cyan. Beeswarm boxplot of final fruit length and photographs of dehiscence in C. hirsuta wild type, ful1 , and ful-1 complemented with $p C h F U L:: g C h F U L-$

Venus, $p$ ChFUL::gAtFUL-Venus, and pAtFUL::gAtFUL-Venus, coiled valves are shown with dehisced fruit. $\mathrm{N}=>15$ fruit from at least 5 plants for each genotype. Letters denote statistically significant differences $(\mathrm{P}<0.001)$ between means based on one-way ANOVA (Tukey's HSD). (E-G) CLSM showing FUL expression (yellow) in the fruit base of $C$. hirsuta ful-1 complemented with $p C h F U L:: g C h F U L-V e n u s(\mathrm{E}), p C h F U L:: g A t F U L-V e n u s$ (F), and pAtFUL::gAtFUL-Venus (G); chlorophyll autofluoresence in blue. Representative $\mathrm{T} 2$ lines of 10 independent transgenic lines shown in $(\mathrm{E}, \mathrm{F})$ and progeny of a representative T1 line crossed to ful-1 shown in (G). Abbreviations: v: valve, r: replum. Scale bars: $1 \mathrm{~mm}$ (A, D) $10 \mu \mathrm{m}(\mathrm{B}, \mathrm{C}), 50 \mu \mathrm{m}(\mathrm{E}-\mathrm{G})$. 

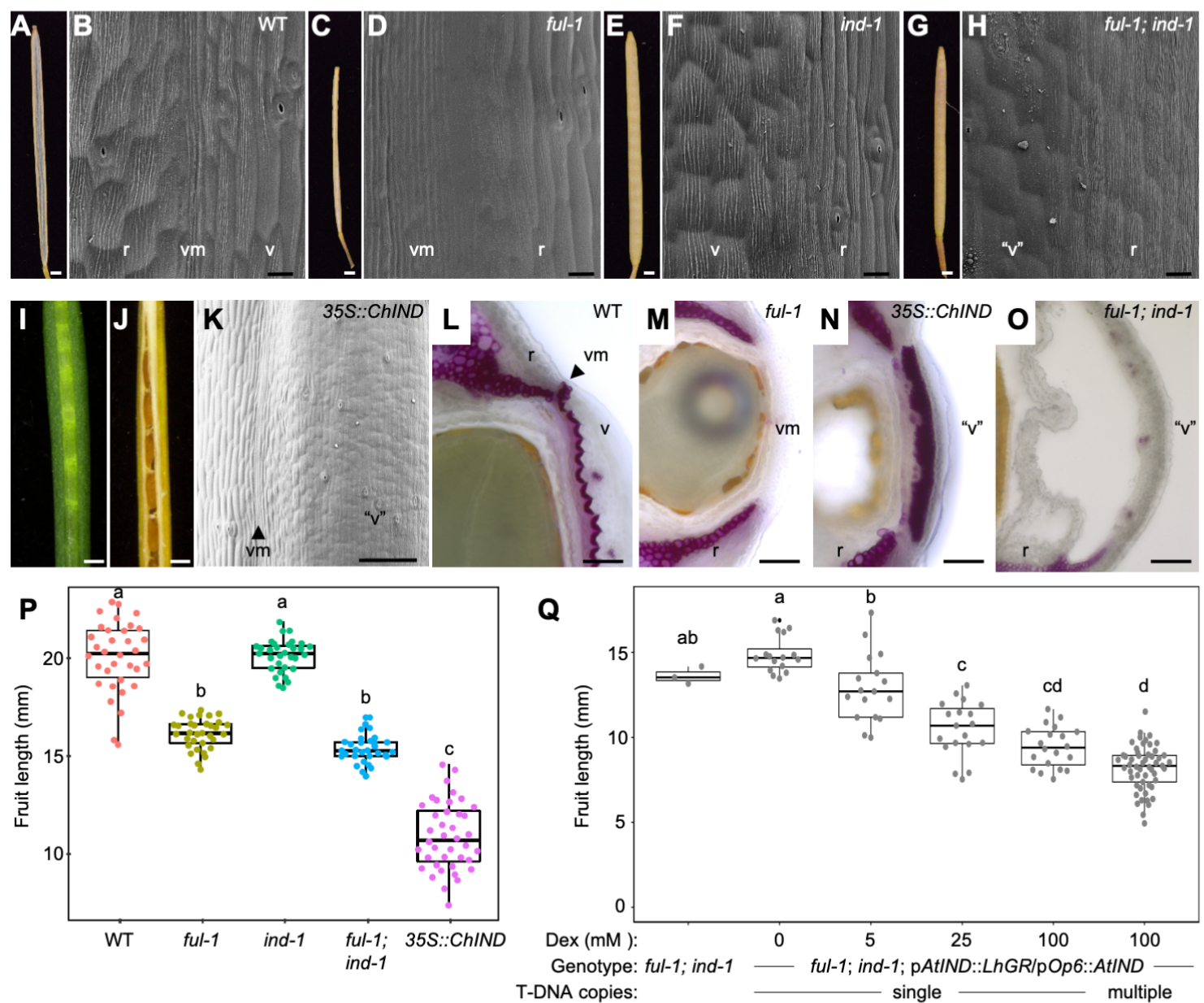

Figure 6. $C$. hirsuta ful phenotype is IND-dependent. (A-K) C. hirsuta fruit and SEMs of the fruit surface in dehiscent wild type (A, B) and indehiscent ful-1 (C, D), ind-1 (E, F), ful-1;ind-1 (G, H), and 35S::ChIND (I-K). (L-O) Phloroglucinol stained transverse sections of $C$. hirsuta fruit of the following genotypes: wild type (L), ful-1 (M), 35S::ChIND (N) and ful-1;ind-1 (O). (P) Beeswarm boxplot of final fruit length in $C$. hirsuta wild type, ful-1, ind-1, ful-1;ind-1, and 35S::ChIND, $\mathrm{n}=>30$ fruit from 5 plants for each genotype including 4 independent 35S::ChIND T2 lines. (Q) Beeswarm boxplot of final fruit length in C. hirsuta ful-1;ind-1 and ful-1;ind-1; pAtIND::LhGR/pOp6::AtIND homozygous T3 plants with single or multiple T-DNA insertions, treated with dexamethasone concentrations of $0,5,25$ or $100 \mu \mathrm{M}, \mathrm{n}=128$ fruit from 4 (single T-DNA) and 8 (multiple T-DNA) independent transgenic lines. Letters denote statistically significant differences $(\mathrm{P}<0.05)$ between means based on one-way ANOVA (Tukey's HSD). Abbreviations: $r$, replum; v, valve; vm, valve margin; "v". modified valve. Scale bars: $1 \mathrm{~mm}$ (A, C, E, G), 0.5 mm (I-J), $20 \mu \mathrm{m}$ (B, D, F, H), $100 \mu \mathrm{m}$ (K), $50 \mu \mathrm{m}$ (L-O). 